\title{
Condition-based maintenance methods for marine renewable energy
}

\author{
Alexis Mérigaud*, John V. Ringwood \\ Centre for Ocean Energy Research, Department of Electronic Engineering, Maynooth University, Maynooth, Ireland
}

\section{A R T I C L E I N F O}

\section{Article history:}

Received 2 October 2015

Received in revised form

7 April 2016

Accepted 21 July 2016

\section{Keywords:}

Marine renewable energy

Offshore wind turbine

Wave energy converter

Tidal turbine

Condition-based maintenance

Condition monitoring

Fault diagnosis

Fault prognosis

\begin{abstract}
A B S T R A C T
With an increasing requirement to lower the costs of delivered renewable energy, the maintenance costs for marine renewable energy (MRE), due to accessibility issues, are an obvious focal point. In particular, condition-based maintenance and prognostics can help to optimise maintenance activities and forewarn of impending maintenance requirements, mindful of the constrained access to MRE systems due to limited weather windows of sufficient duration.

This paper focusses on offshore wind, tidal flow and wave energy as target MRE domains and provides a comprehensive review of condition-based maintenance methodologies currently employed in MRE systems. While, of the three energy domains, offshore wind is the more mature, giving the opportunity to propagate such methods to the less mature areas of tidal and wave, there are also many components and challenges which are common to all three domains, e.g. generator systems and grid interface.
\end{abstract}

(c) 2016 Elsevier Ltd. All rights reserved.

\section{Contents}

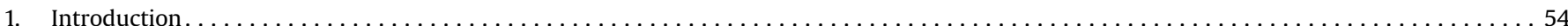

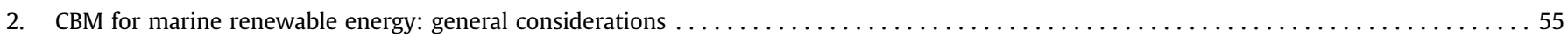

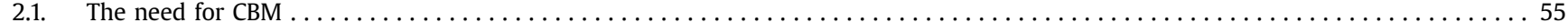

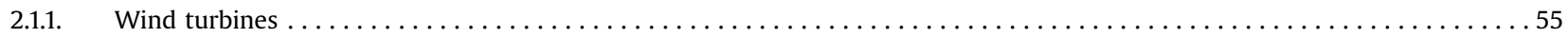

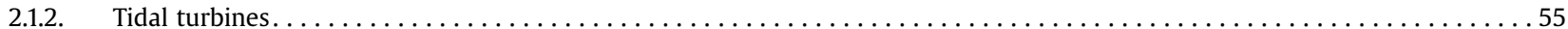

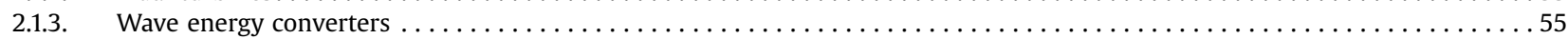

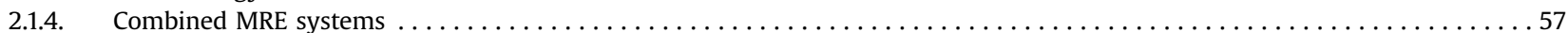

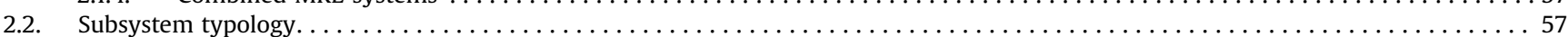

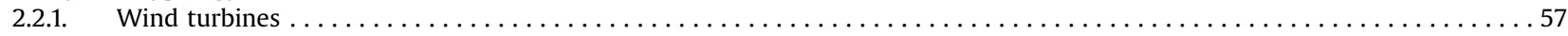

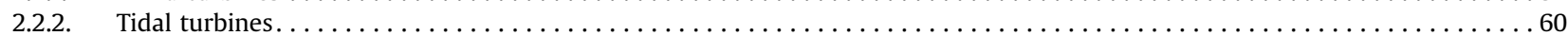

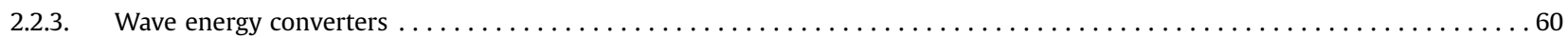

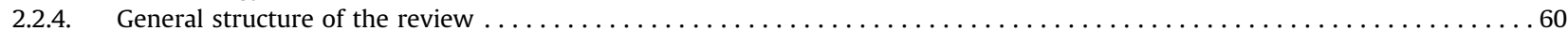

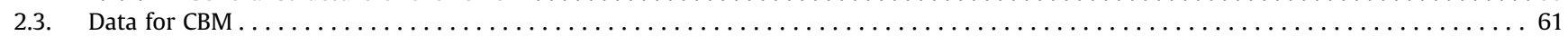

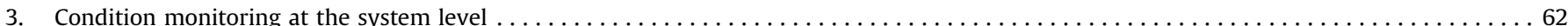

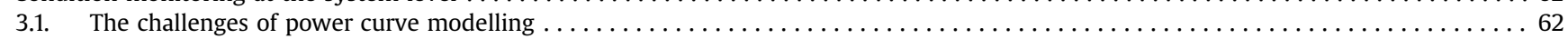

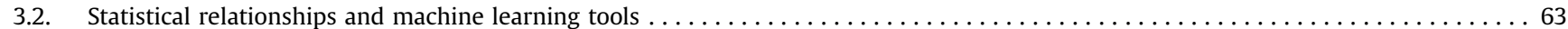

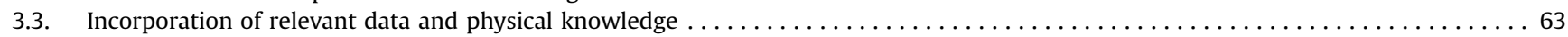

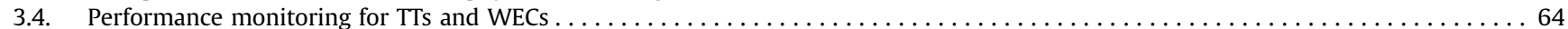

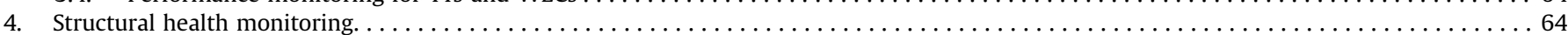

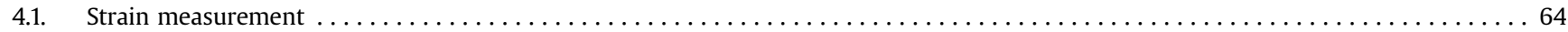

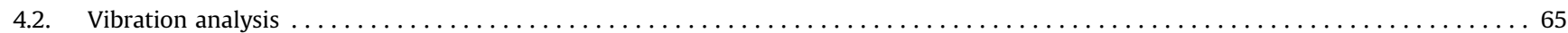

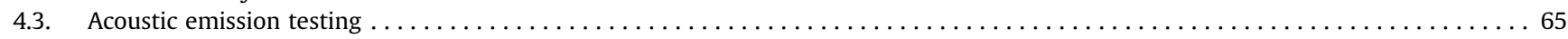

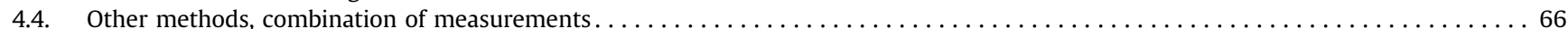

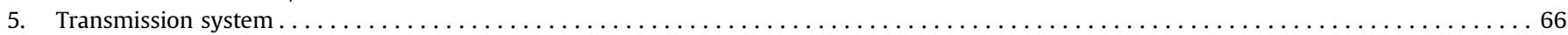

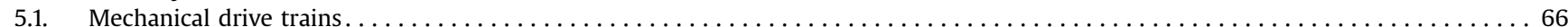

\footnotetext{
* Corresponding author.

E-mail address: alexis.merigaud@gmail.com (A. Mérigaud).
} 


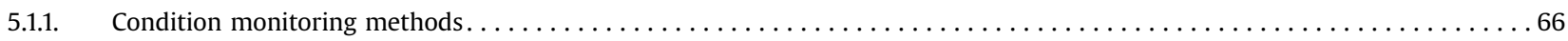

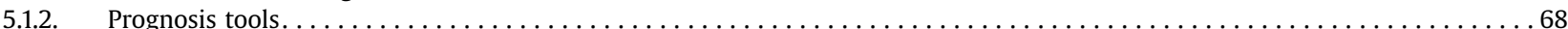

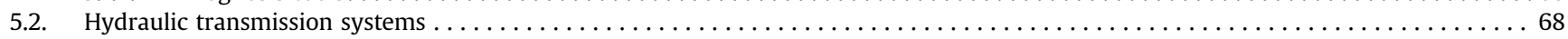

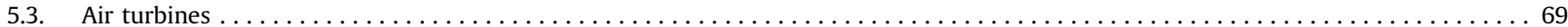

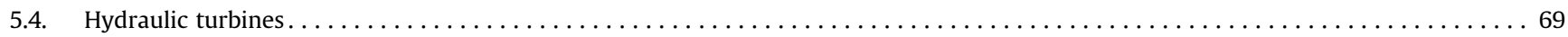

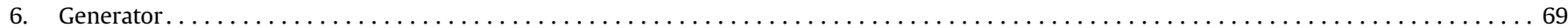

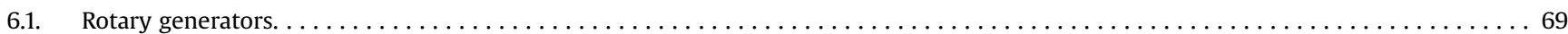

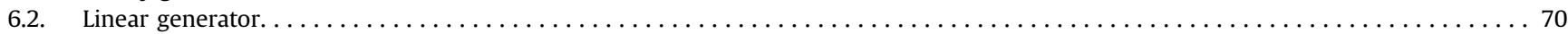

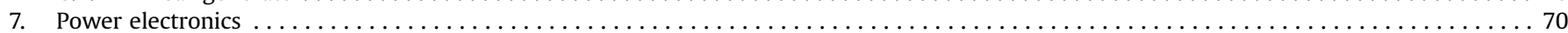

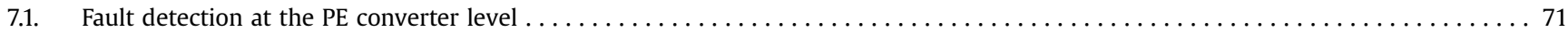

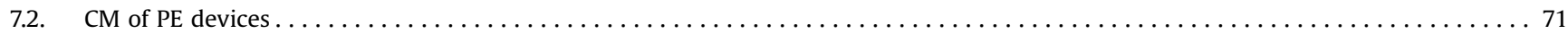

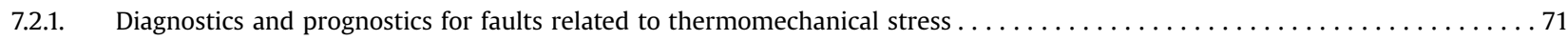

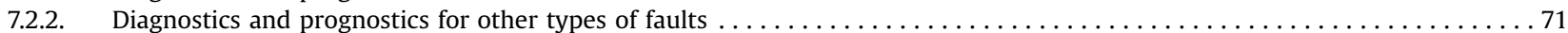

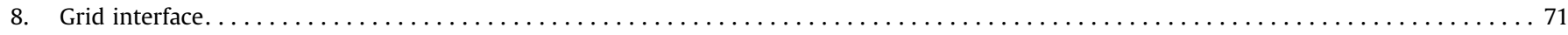

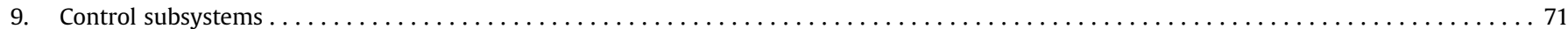

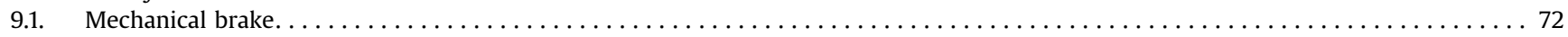

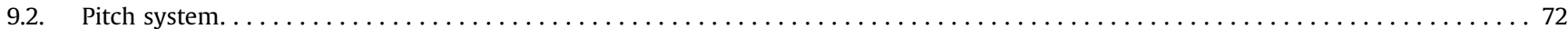

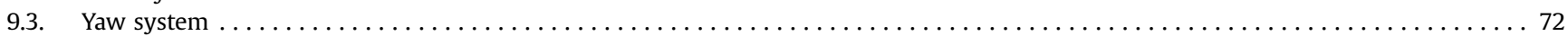

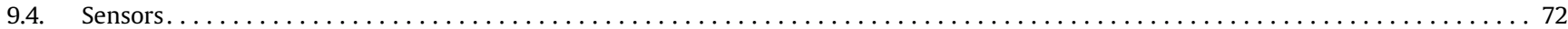

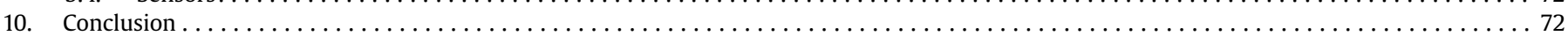

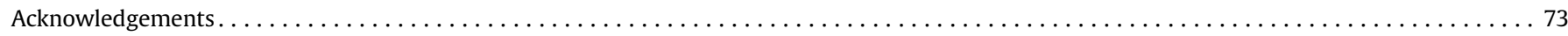

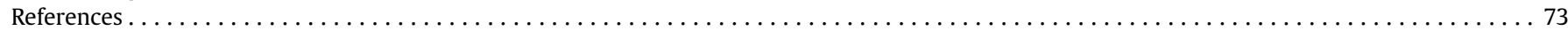

\section{Introduction}

Concerns about global warming and dependence on fossil fuels have generated considerable interest in renewable power generation technologies over the past three decades. In many industrialised countries, especially in Europe, the growth of renewable energy production capacity has been strongly supported by public authorities [1]. Amongst other technologies, the potential of marine renewable energy (MRE) sources is being increasingly explored.

MRE technologies are particularly challenging in terms of installation, operation, maintenance and survivability. Varying operating speed and load, corrosion, sea life, structural stresses induced by wind, wave and current, all represent threats to the survivability of MRE systems. Furthermore, the location at a long distance from shore and the need for specific vessels make installation, operation and maintenance more costly and challenging. For a given failure rate, a device located offshore will experience more downtime than onshore, since accessibility requires a favourable weather window. On-line condition-based maintenance ( $\mathrm{CBM}$ ) has the potential to increase availability and reduce maintenance costs, and hence improve the competitiveness of MREs with other power production technologies.

CBM can be defined as the "continuous monitoring of system data to provide an accurate assessment of the health, or status, of a component or system and performing maintenance based on its observed health" [2]. It implies that system data are monitored and processed in real-time by a condition monitoring (CM) system. Ideally, a CBM system is able to perform:

- system or component diagnosis, which consists of fault or failure detection, isolation and identification, and/or

- system or component prognosis, which relies on estimates of the remaining useful life (RUL) of the system or component.

CBM goes beyond fault diagnosis and prognosis: firstly, a typology of components and related failures has to be established and prioritised, through methods such as failure modes effects and criticality analysis (FMECA) [3,4]. Furthermore, CBM extends to the development of a whole strategy which takes into account not only diagnosis and prognosis results, but also parameters such as expected weather windows and other schedule constraints [5-7]. Finally, financial aspects also enter into consideration in CBM strategy design [8-10]. In spite of the importance of these additional aspects, the focus of this review is on techniques for fault diagnosis and prognosis in MRE systems, with emphasis on the applicability of the methods presented to automated, on-line systems.

Unlike other MREs, offshore wind is a mature, plentifully deployed, and well-standardised industry [11]. In Europe, in 2014, $\$ 18.6$ billion were invested in offshore wind projects [1], and the available offshore wind capacity at the end of 2014 exceeded $8 \mathrm{GW}$, according to the European Wind Energy Association (EWEA). The onshore and offshore wind industry has already carried out significant research to develop reliable CBM strategies for wind turbines (WTs).

In contrast, the total installed capacity of other MRE systems worldwide amounted to only $530 \mathrm{MW}$ in 2012, with $517 \mathrm{MW}$ from tidal barrages alone. In Europe, about $40 \mathrm{MW}$ of tidal and $26 \mathrm{MW}$ of wave energy capacity are expected to be installed by 2018 [12]. Non-wind MRE sources are still at an early development stage [13], and their designs are still much more diverse than offshore wind turbine (OWT) designs. As a consequence, the implementation of maintenance strategies for non-wind MRE systems has received less attention. The blatant resulting imbalance in terms of available literature is reflected in this review.

However, many similarities can be found between most marine energy power generation systems, whether it be in their general structure and essential components [11], or in the various challenges presented by the ocean environment [14-17]. Wave energy converters (WECs) and tidal turbines (TTs), in particular, share a lot with OWTs. WTs, TTs and WECs are all complex engineering structures that capture the fluid energy through external moving parts. Electrical components (generators, power converters and transformers) are also common across these three applications. Therefore, a joint review of CBM methods applicable to OWTs, TTs and WECs can be useful to highlight the possible synergies as well as the specificities of each technology in terms of requirements towards the development of CBM techniques. Another distinctive feature of the present review is that techniques for CBM are successively 
presented for each of the main subsystems of MRE converters, which has two significant advantages: Firstly, this structure allows for a presentation of CBM techniques on a tangible basis, and secondly it considers both the subsystems for which the literature is abundant and the components which could deserve more attention than they have received to date.

In summary, this review is aimed at MRE researchers and developers working on CBM, and has the following objectives:

- Orient them quickly towards the most relevant references on CBM for any specific subsystem of interest, including more specialised reviews.

- Whenever it is possible, and in spite of the variety of valuable works, highlight studies or techniques that seem to be the most advanced or promising.

- Make the research community aware of components that are still overlooked in terms of CBM and would deserve more investigation.

- Finally, this review should be particularly useful to researchers and engineers trying to develop CBM techniques for wave and tidal energy converters: despite the paucity of literature on CBM for these two technologies, relevant analogies and specificities should be identifiable, and appropriate techniques, used in the field of wind energy, which could be transposed to corresponding TT and WEC subsystems, chosen. The specific requirements and challenges for some TT and WEC subsystems, in terms of necessary measurement and modelling effort, are also discussed.

To assist in reaching these goals, the main results are summarised in tables (Tables 1-7), offering the reader a quick overview prior to accessing the detailed analysis if necessary.

In Section 2, the general issues of CBM for MRE are discussed. In particular, the need for CBM is briefly highlighted, the issue of data acquisition is addressed, and the different components possibly found in WTs, TTs and WECs are identified so that CBM issues are discussed on a tangible basis. Sections 3-9 reflect the subsystem typology outlined in Section 2: condition monitoring at the system level (3), structural health monitoring (4), transmission system (5), generator (6), power electronics (7), grid interface (8), and controlspecific subsystems (9). Finally, the conclusion (10) summarises the main observations to retain, whether they be general or specific to some subsystems or MRE technology, and highlights recommendations and challenges to address, especially for WEC and TT CBM development.

\section{CBM for marine renewable energy: general considerations}

\subsection{The need for $C B M$}

\subsubsection{Wind turbines}

Early experience of offshore wind farm operators showed that the availability rate of OWTs was lower than expected, and that a quarter to one third of the total cost of offshore wind energy is attributable to operation and maintenance $[18,19]$. Maintenance costs for OWTs are significantly higher than those of onshore WTs $[18,19]$. The fact that offshore wind farms are built in increasingly remote sites makes appropriate maintenance scheduling even more essential. Furthermore, as WTs get bigger, the financial losses due to individual WT downtime also grow [20]. The benefits of CBM for OWTs are then well recognised $[18,8,21,22]$. CBM is now widespread in the wind industry [23], an abundant literature about CBM for WTs already exists, and many reviews related to WT CBM have been published [23$35,22]$.

It may be noted that most methods which can be applied to OWTs do not fundamentally differ from those that are used for onshore WTs. That is why, in the present review, techniques for CBM of WTs are more often presented irrespective of their application to onshore or offshore WTs.

\subsubsection{Tidal turbines}

In order to reach economic competitiveness, TT concepts have to overcome major challenges related to installation, maintenance, electricity transmission, loading conditions and environmental impacts [36].

A review of the various tidal current extraction technologies under development can be found in [37]. To date, most concepts under development are horizontal axis tidal turbines (HATTs) [37]. In particular, all the large marine TT projects - i.e. exceeding $500 \mathrm{~kW}$ - reported in [38] are HATTs. This is why, unless otherwise specified, the TTs considered in the present paper are HATTs. However, even amongst HATTs, designs still differ a lot, for example in the number of blades [38] or in the design of the supporting structures [39].

The particularly challenging operating conditions of TTs have been well described $[15,39,40]$. In broad outline, most damage caused by the operating environment of TTs can be categorised into hydrodynamic loads, erosion/corrosion, and biofouling $[39,15,41,42,14]$, although these factors are often interrelated. Some examples of TT failures due to hydrodynamic loads and biofouling can be found in [4]. Maintenance requirements have strongly influenced TT designs such as the twinned SeaGen, Alstom's Oceade and the OpenHydro TTs.

To some extent, knowledge transfer from wind and ship propeller industries is to be expected, since many components and operational challenges are common across these applications. However, the operating conditions of TTs show significant specificities [39,43], which means that a direct transposition of methods applied to WT components is not possible. A research effort specific to TT CBM is therefore necessary.

\subsubsection{Wave energy converters}

Ocean waves represent a vast, untapped resource estimated at 2 TW [44], or 32,000 TW h per year [45]. However, wave power

Table 1

General issues on CBM for marine renewable energy technologies.

Need for CBM
Available literature on Data for CBM

CBM

Abundant: reviews found in [22-35]

gusts, waves, distance from shore, high capital cost [8,18-22

Scarce

WECs Strong: extreme waves, strong and intermittent operating loads, corrosive en- Scarce high capital cost [15,39-42,14,4] vironment, biofouling, distance from shore, high capital cost [14,39]
SCADA data [57], commercial condition monitoring systems [55]

Bespoke measurement systems

Bespoke measurement systems on scaled devices and prototypes [58-60] 
Table 2

CBM through system performance monitoring.

Challenges and critical issues

OWTs Modelling input/output relationships

Methods

Pros \& cons

Simplicity

Machine learning: ANN [70,75,74], GP [68,74], GMM [65], other methods and comparative studies [72,75$77,61,65,73,70]$

Physical-statistical model [72]

Appropriate input data (in addition Air density (or equivalent quantity such as air temperato wind speed and direction) Air density (or equ
ture) $[68,61,75-79$

Other SCADA data (system duty, binary status, etc.) $[72,66]$ SCADA data from other WTs $[79,70,69,74]$
Ability to easily model nonlinear input/output relationships

Simple, informative, effective

Crucial data to reduce output variance

Also reduces output variance

Detect outliers, replace missing data, improve diagnosis reliability

TTs Input/output relationship

Appropriate input data

WECs Input/output relationship

Appropriate input data

Recommendations and remarks

-It is uneasy to determine whether there is one unique preferable method (in comparative studies several methods exhibit comparable performance on considered datasets).

-Clustering methods and GMMs intuitively model multi-regime processes.

GPs naturally provide information on the confidence of the output prediction -ANNs generally exhibit good performance in comparative studies.

-Incorporating physical knowledge into the model [72] is highly recommended. -Incorporation of relevant input is crucial. Simple models with enough input -lncorporation of relevant input is crucial. Simple models with outperform complex models with less input data.

data can outperform complex models with less input data.

-In particular incorporating air density when possible is highly recommen

-Using other available SCADA data to monitor the performance of specific

subsystems is valuable. Examples of data choices are fo
-Data from surrounding WTs can be successfully used.

- TT power curves are well-defined provided that upstream flow velocity and water density are known

-The upstream flow velocity should be measured or estimated

-If the flow is estimated, waves in the area must be taken into account

-Water density should be measured or estimated.

- Involves modelling of complex hydrodynamics or that a power matrix has

previously been built
-Free surface elevation may be measured or estimated.

- Flee surface elevation may be measured or estimated. wave spectrum) 
extraction technologies are still in an early development stage, being very far from competitiveness with other energy sources [46]. WEC survivability in the marine environment brings significant engineering challenges, since structures must be designed to face extreme waves and the highly corrosive environment at the sea surface, resulting in very high capital costs [44]. WECs are even less standardised than TTs, as illustrated by the close to 1000 wave energy conversion techniques which have been patented in Europe, North America and Japan [44].

As reviewed in [14], the hydrodynamic environment and biofouling both represent significant threats for WEC survivability. Critical tribological components are identified in [39]: hydraulic system, pistons and cylinders, hinge, bearings, sliding and rotating seals and embedded turbines must all be compatible with the marine environment. However, similarly to TTs, very little research has been proposed on CBM of WECs.

\subsubsection{Combined MRE systems}

This subsection is concluded by a final discussion about the specific aspects of combined MRE systems. Combined MRE systems mainly associate wind and wave energy - since resource combination involving TTs has much less potential [47]. Combined wind-wave systems can be [47]:

- co-located systems, in which OWTs and WECs share "the same marine area, grid connection, O\&M equipment and personnel [and] port structures" into a unique farm,

- hybrid systems, which combine an OWT and a WEC on the same structure,

- or island systems, that are similar to hybrid systems but much bigger, and may combine more than two marine resources.

The combination of OWTs and WECs has positive implications in terms of maintenance costs and needs. Firstly, O\&M costs would be shared between the two resources, hence contributing to electricity cost reduction for both technologies. Secondly, [47] points out the "shadow effect" induced by the presence of WECs: by absorbing a significant fraction of the wave energy in the vicinity of OWTs, WECs may act as shields, thus reducing the loads on structures and making maintenance easier by increasing the length and number of suitable weather windows for maintenance operations on the farm.

Conversely, combining WECs and OWTs into a same farm creates new types of risks for the latter, since WEC mooring failure might result in catastrophic collision.

\subsection{Subsystem typology}

Within the scope of this review, it is important to have an overview of the technologies used for the different possible energy conversion stages, and the associated components.

\subsubsection{Wind turbines}

As far as wind turbines are concerned, the drive train mechanical components and, to a lesser extent, the rotating blades, have received the most attention in the literature and in commercially available CM systems. However, there is no consensus with regard to which components should receive more attention [48]. Other WT components seem to be at least as prone to failure and should not be overlooked in any OWT CBM system, in particular components related to power electronics (PE) and control [20], which are relatively overlooked in most reviews dedicated to CBM of WTs and therefore will receive more attention in the present review. 
Table 4

Transmission system CBM techniques for marine renewable energy devices.

\begin{tabular}{|c|c|c|c|c|c|c|}
\hline Type & Method & & General comments & WT & TT & WECS \\
\hline \multirow[t]{8}{*}{$\begin{array}{l}\text { Mech. Drive } \\
\text { Train }\end{array}$} & Diagn. & VA & - Necessitates data processing + feature classification. & - Review in [35]. & $\begin{array}{l}\text { - Applicable vibration data } \\
\text { processing and analysis tools } \\
\text { investigated in }[151]^{1} .\end{array}$ & $\begin{array}{l}\text { - Limitation: applicability to } \\
\text { WECs is questionable given the } \\
\text { nature of WEC dynamics }\end{array}$ \\
\hline & & & $\begin{array}{l}\text { - Data processing: TD [125] }]^{1}[126]^{1} \mathrm{FD}[104],[127],[130]^{1}, \mathrm{~T}-\mathrm{F} \\
\text { analysis (STFT, WT, CCD, EMD) [132,134,135,139,140], or ana- } \\
\text { lysis of alternative signals. Comparison of T-F representations } \\
\text { in [142]. }\end{array}$ & $\begin{array}{l}\text { - Signal processing: Time-domain }[122]^{4} \text {, frequency- } \\
\text { domain }[128]^{4}, \text { WT }[131]^{4}[133]^{1,2}, \text { EMD }[136]^{4}, 2[137]^{4} \\
{[138]^{4}[141]^{1}, 2, \text { comparative study }[124]^{1} .}\end{array}$ & $\begin{array}{l}\text { - Feature selection and data } \\
\text { fusion }[152],[153]^{1}[154]^{1}[155]^{1}\end{array}$ & \\
\hline & & & $\begin{array}{l}\text { - Data classification: SVM may have better generalisation } \\
\text { capability and shorter learning time than ANN. Limitations of } \\
\text { machine learning methods include the need for abundant } \\
\text { historical data. Comparative studies }[145]^{1}[144]^{1}\end{array}$ & $\begin{array}{l}\text { - Feature extraction and classification: ANN }[133]^{1,} \\
{[143]^{1} \text { SVM }[146]^{2}[147]^{4}[148]^{1}}\end{array}$ & & \\
\hline & & & & $\begin{array}{l}\text { - Alternative signals: }[26]^{4}[150]^{1} \\
\text { - } 27 \text { commercially-available systems [55] }\end{array}$ & & \\
\hline & & $\mathbf{O A}$ & $\begin{array}{l}\text { Review in [34]. Still expensive, but enables very reliable, direct } \\
\text { and precise diagnosis, for example through transient detec- } \\
\text { tion }[157]^{1} \text {. Applicable to the } 3 \text { technologies. }\end{array}$ & $\begin{array}{l}{[156]^{1} \mathrm{OA} \text { included in } 10 \text { commercially-available sys- }} \\
\text { tems [55]. }\end{array}$ & $\begin{array}{l}\text { OA could be equally applicable } \\
\text { to TTs }\end{array}$ & $\begin{array}{l}\text { OA could be equally applicable to } \\
\text { WECs }\end{array}$ \\
\hline & & Other & $\begin{array}{l}\text { EA }[160]^{1}[161]^{1}[159]^{1}[162]^{1}[163]^{2} \text { is cheap and can replace } \\
\text { shaft torque measurement }[164]^{1} \text {, but cannot cover all failure } \\
\text { modes. Shock-Pulse Method }[104],[168]^{2}, \text { AE }\end{array}$ & EA $[164]^{1}[165]^{1}[166]^{1}, \mathrm{AE}[169]^{4}$, torque $[119]^{1}[164]^{1}$ & & \\
\hline & & $\begin{array}{l}\text { Comb. of } \\
\text { data }\end{array}$ & $\begin{array}{l}\text { It is encouraged to use the complementarity of different } \\
\text { measurements to improve reliability. }\end{array}$ & $\begin{array}{l}\text { Temperature + other SCADA data }[72]^{1}[170]^{4}[171]^{4} \\
{[172]^{4}, \text { SCADA + VA }+ \text { OA }[56]^{4}, \mathrm{VA}+\mathrm{AE}[169]^{4}}\end{array}$ & $\mathrm{VA}+\mathrm{AE}: \mathrm{EU}$ REMO project & \\
\hline & Progn. & & $\begin{array}{l}\text { Reviews in }[174,175,149] \text {. Data-based prognostics for non- } \\
\text { linear and non-stationary rotating systems are reviewed in } \\
{[149]}\end{array}$ & $\begin{array}{l}\text { Extended Kalman filtering, SVM and Fuzzy-logic may } \\
\text { be the less demanding methods in terms of data re- } \\
\text { quirements [149]. }\end{array}$ & $\begin{array}{l}\text { Fatigue load model }[42]^{1,}, \\
{[176]^{2}}\end{array}$ & Fatigue load model $[53]^{2},{ }^{3}$ \\
\hline Hyd. PTO & \multicolumn{6}{|c|}{$\begin{array}{l}\text { Suitable for the } 3 \text { applications - would justify significant research effort. Leakage detection would be critical. Possible methods could be transposed from other applications, such as physical model }[180]^{2} \text {, }[181]^{2} \text {, } \\
{[182]^{2} \text {, data-driven approach }[184]^{1} \text {, or model-free signal processing }[183]^{1} \text {. Review of available methods in }[183]}\end{array}$} \\
\hline Air Tur. & \multicolumn{6}{|c|}{$\begin{array}{l}\text { More investigation and experience from operating oscillating water columns are } \\
\text { needed to assess reliability and CBM needs }\end{array}$} \\
\hline Hyd. Tur. & \multicolumn{6}{|c|}{$\begin{array}{l}\text { Possible transfers from ship propellers }[186]^{1},{ }^{2} \text { or hydroelectric industry }[187]^{4} \text {, } \\
{[188]^{1}{ }^{1}{ }^{4} \text {. But WEC turbines are much smaller than hydroelectric turbines. }}\end{array}$} \\
\hline
\end{tabular}

Superscripts indicate whether methods are tested on data. 1-from physical experiments in laboratory. 2-from numerical simulations. 3-recorded on scaled models. 4-from operating full-scale devices. 
Table 5

Generator CBM techniques for marine energy devices

\begin{tabular}{|c|c|c|c|c|}
\hline Type & General comments & WT & TT & WECS \\
\hline $\begin{array}{l}\text { Rotary } \\
\text { Gen. }\end{array}$ & $\begin{array}{l}\text { - Reviews of rotating electrical machine CM techniques } \\
{[190,191,189,30] \text {. }} \\
\text { - Traditional method: MCSA (not suitable for varying-load } \\
\text { applications). } \\
\text { - Diagnosis techniques for nonstationary applications are re- } \\
\text { viewed in [30]. T-F analysis is found to be more suitable than } \\
\text { frequency-domain, time-domain and slip-frequency analysis. }\end{array}$ & 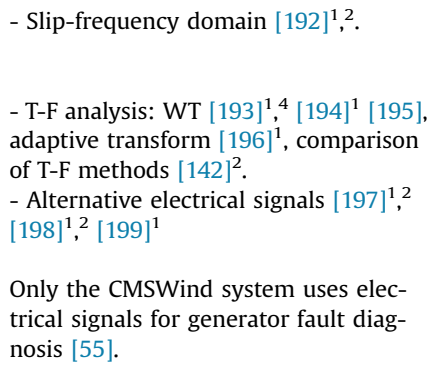 & $\begin{array}{l}\text { Electrical signals could present less } \\
\text { strong variability and transients than in } \\
\text { WTs, making fault diagnosis easier. }\end{array}$ & $\begin{array}{l}\text { - In case the generator is decoupled from the device motion } \\
\text { through a hydraulic PTO, signal variability and transients } \\
\text { could be less strong than for WTs. } \\
\text { - In case the generator is coupled to the device motion } \\
\text { through a mechanical drive train the generator load varia- } \\
\text { bility could have unique features requiring specific studies. }\end{array}$ \\
\hline $\begin{array}{r}\text { Linear } \\
\text { Gen. }\end{array}$ & $\begin{array}{l}\text { CBM for linear generators would deserve investigation given } \\
\text { the number of WEC concepts including a linear generator. }\end{array}$ & & & $\begin{array}{l}\text { Critical quantities to monitor could be [59]: } \\
\text { - Electrical quantities, } \\
\text { - Generator temperature, } \\
\text { - Water level inside the generator, } \\
\text { - Translator position, } \\
\text { - Forces experienced at the extremes of the reciprocating } \\
\text { translator motion. }\end{array}$ \\
\hline
\end{tabular}

Superscripts indicate whether studies are based on data. 1-from physical experiments in laboratory. 2-from numerical simulations, 3 - recorded on scaled models. 4-from operating full-scale devices.

Table 6

CBM techniques for MRE power electronics.

\begin{tabular}{|c|c|c|c|}
\hline Level & General comments & WTs & WECs \\
\hline PE converter & $\begin{array}{l}\text { PE converters are increasingly critical components across the three } \\
\text { applications. } \\
\text { - Open-circuit fault: detection methods reviewed in [207,209,189]. Most } \\
\text { methods are non-invasive and require no sensor. } \\
\text { - Short-circuit IGBT faults [207]: rapidly evolve to catastrophic failures. Pro- } \\
\text { tection schemes implemented in hardware. }\end{array}$ & $\begin{array}{l}{[201]^{1}, 2 \text { : observer-based method for open-cir- }} \\
\text { cuit fault detection in a WT PMSG power } \\
\text { converter }\end{array}$ & - Identical methods could be implemented for TTs and WECs. \\
\hline PE device & $\begin{array}{l}\text { PE converters are increasingly critical components across the three } \\
\text { applications. } \\
\text { Review of CM and prognostics for IGBT PE in [212]. } \\
\text { - Faults due to thermomech. stress: for nonstationary applications, mainly } \\
\text { model-based prognosis methods are suitable [211]. } \\
\text { - Other faults: for WTs, other damage causes may be more important }[217]^{4} \text {, } \\
\text { such as electrical overstress and insufficient protection against salt and } \\
\text { condensation. These deserve more investigation. }\end{array}$ & $\begin{array}{l}\text { - WT PE RUL estimation }[213]^{2} \text {, } \\
\text { - Comparison of offshore and onshore WT PE } \\
\text { reliability [214] } \\
\text { - Effects on the WT PE RUL: of wind speed [215] } \\
\text { and of WT control }[216]^{2}\end{array}$ & $\begin{array}{l}\text { - Given specific control strategies and operating conditions of TTs and WECs, } \\
\text { specific work is needed to adapt PE prognosis techniques. } \\
\text { - Similarly to WTs, environmental threats (salt, etc.) could be prominent failure } \\
\text { causes. }\end{array}$ \\
\hline
\end{tabular}

Superscripts indicate whether studies are based on data. 1-from physical experiments in laboratory. 2-from numerical simulations, 3 - recorded on scaled models. 4-from operating full-scale devices. 
Table 7

CBM techniques for various marine renewable energy subsystems.

\begin{tabular}{|c|c|c|c|c|}
\hline Subsystem & General comments & WTs & TTs & WECS \\
\hline Grid interface & $\begin{array}{l}\text { - Elec. configurations for MRE farms [51,11]. Critical components: low- } \\
\text { voltage, high-voltage and grounding transformers [218]. } \\
\text { - CM of power transf. is common practice (review in [221]): dissolved gas } \\
\text { analysis, temperature monitoring, partial discharge analysis, frequency } \\
\text { response analysis. }\end{array}$ & $\begin{array}{l}\text { Low-voltage transf. are reported to } \\
\text { fail prematurely [219,220] due to } \\
\text { - variable load of WTs resulting in } \\
\text { thermal cycling, } \\
\text { - harmonic content of the WT power } \\
\text { output. }\end{array}$ & $\begin{array}{l}\text { - Identical } \\
\text { plemented }\end{array}$ & $\begin{array}{l}\text { methods could be im- } \\
\text { for TTs and WECs. }\end{array}$ \\
\hline Mech. brake & \multicolumn{4}{|c|}{$\begin{array}{l}\text { - Important in WTs and TTs, but CBM of mechanical braking system is still underdeveloped [225]. } \\
\text { - Possible measurements for diagnostics }[226]^{2} \text { : MCSA for faults in the hydraulic system and in the three-phase motor, } \\
\text { non-contact temperature and displacement measurement for faults in the brake disc and calliper. }\end{array}$} \\
\hline Pitch & \multicolumn{4}{|c|}{$\begin{array}{l}\text { - Methods for pitch system diagnostics: } \\
\text { - Data-driven proposed in }[227]^{4} \text {. Reduces the number of alarms to handle manually and generates meaningful rules. } \\
\text { - Only one commercial product (Condition Diagnostics System) includes a pitch system CM option [55]. } \\
\text { - In TTs including a pitch mechanism, fault diagn. and fault-tolerant control will be as relevant }\end{array}$} \\
\hline Yaw & \multicolumn{4}{|c|}{$\begin{array}{l}\text { - No studies dedicated to yaw mechanism fault detection have been published. However } 2 \text { commercially-available WT CM } \\
\text { systems include yaw system CM features [55] } \\
\text { - WT yaw errors could be detected by elec. power frequency analysis }[121]^{1}{ }^{2} \text {, (cheap solution), or accurately estimated } \\
\text { through LIDAR wind measurements }[233]^{4} \text { (at the cost of LIDAR sensor). } \\
\text { - Some TT concepts include yaw mechanisms. }\end{array}$} \\
\hline Sensors & $\begin{array}{l}\text { Sensor fault detection techniques can be model-based and aimed at } \\
\text { fault-tolerant control. }\end{array}$ & $\begin{array}{l}\text { Model-based methods }[234]^{2}[235]^{2} \\
{[236]^{2}[237]^{2} \text {. }}\end{array}$ & & $\begin{array}{l}\text { WEC modelling is more } \\
\text { complex. }\end{array}$ \\
\hline
\end{tabular}

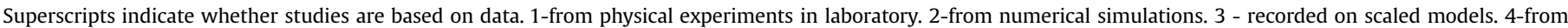
operating full-scale devices.

Two WT concepts are currently dominating the market $[49,50]$ :

- The variable-speed WT with a DFIG and a part-scale power converter (see Fig. 1(a)) is currently the most widespread design.

- The variable-speed WT with an asynchronous or synchronous generator connected to the grid through a full-scale power converter (see Fig. 1(b)) is also popular and is expected to play a more important role in the near future. In WTs equipped with a full-scale power converter, the gearbox can be omitted, which requires the development of specific CBM techniques.

Furthermore, hydraulic-drive and hybrid transmission are promising concepts for future wind turbines [50] and should be considered in the development of new CBM techniques.

\subsubsection{Tidal turbines}

The two main TT configurations are similar to those of modern WTs and thus can be also represented by Figs. 1(a) and 1(b). More

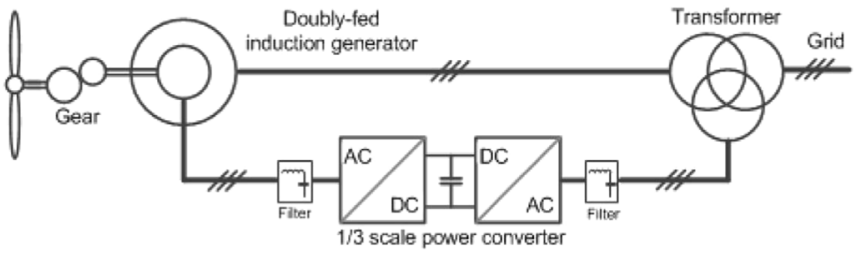

(a)

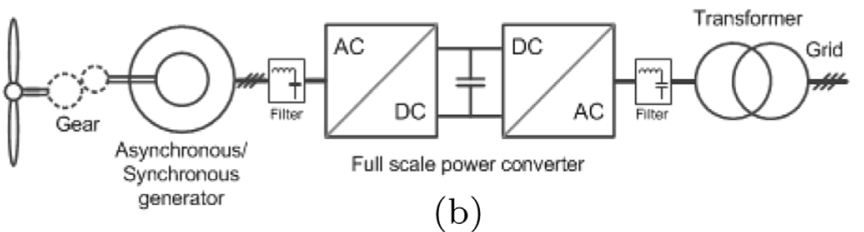

(b)

Fig. 1. The two main types of modern WT and TT configuration [49]: variablespeed turbine with a partial-scale power converter and a DFIG (a) and variablespeed turbine with a full-scale power converter (b). details about possible variants of these concepts and the associated components can be found in [37].

\subsubsection{Wave energy converters}

In spite of the diversity of WEC concepts [44,51], it is possible to establish classifications that allow the study of WECs in a generic way. Inspired by [44,51], five typical wave energy conversion typologies are identified and illustrated in Fig. 2 (from top to bottom):

- Oscillating water columns involve the conversion of the air flux inside the device into the rotation of an air turbine coupled to a generator.

- In overtopping devices, the water collected in the reservoir is released back to the sea through a hydraulic turbine, which is coupled to a generator.

- A typical configuration for floating point absorbers, submersed pressure differential devices, floating attenuators and wave surge devices employs a hydraulic system [51], which is suitable for situations where the oscillating motions are slow. In this case, a piston transfers the motion of the device to the hydraulic system which activates a hydraulic motor, coupled to the generator.

- Although not as common as other energy conversion technologies (and thus not included in most reviews), some concepts such as CorPower [52], StingRay [53] and the BOLT Lifesaver, transfer the motion of the device to a mechanical drive train including rotary bearings.

- Finally, the motions of a floating point absorber or submersed pressure differential WEC can be directly converted into electricity through a linear electrical generator.

\subsubsection{General structure of the review}

Finally, the typology of subsystems that has been retained to structure the present review is illustrated by the dashed, coloured borders in Fig. 2, and can be detailed as follows:

- Whole device or farm - 3: At the widest level, tracking abnormal 


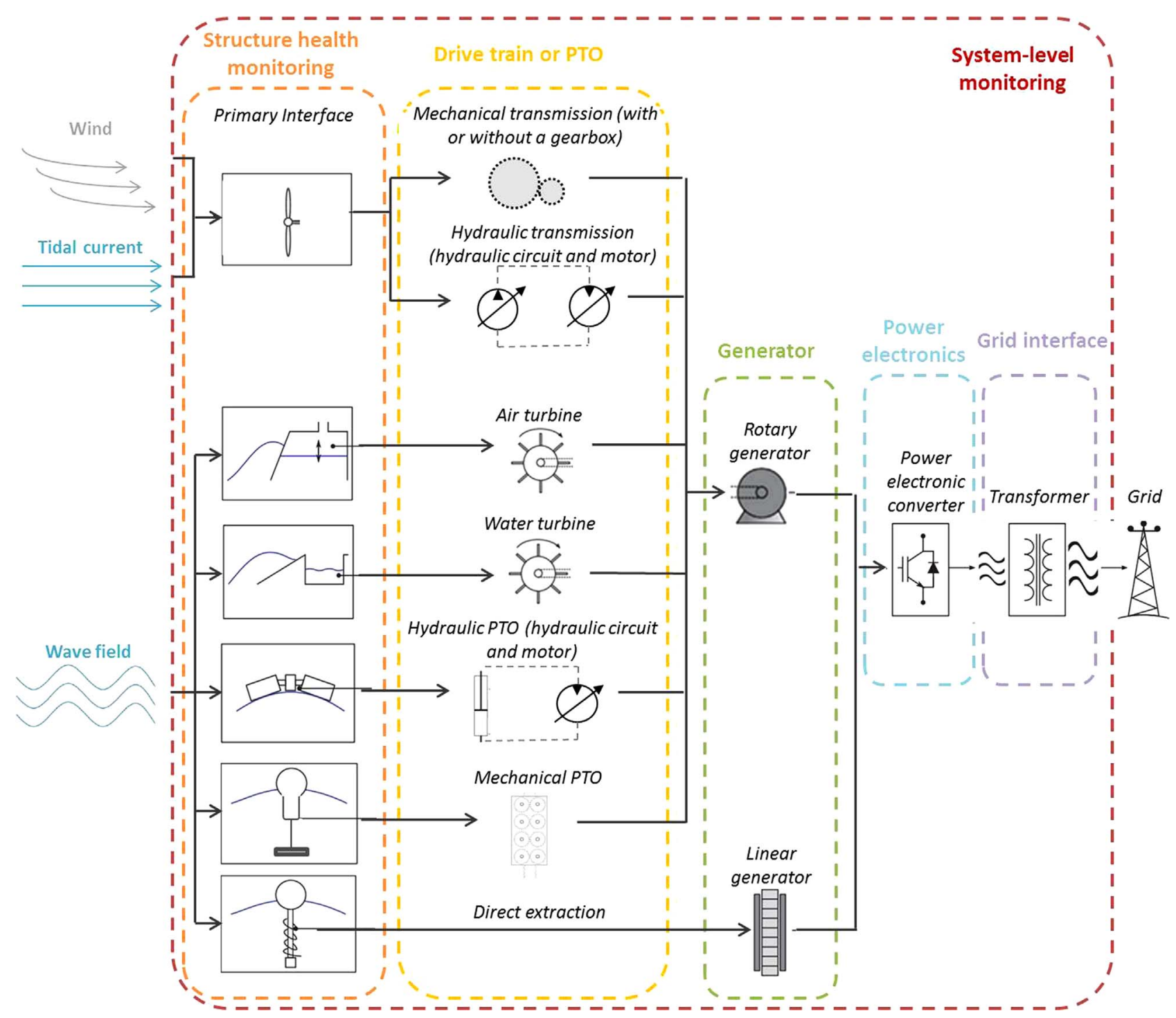

Fig. 2. Classification of WT, TT and WEC subsystems with a view to CBM.

performance of the whole device/farm, can be a cheap and efficient way to detect impending faults.

- Structural components - 4: Structural components of OWTs include tower, nacelle, rotor and blades, transition piece and foundation. Structural components are similar in the case of TTs, but much more diverse in the case of WECs. Structural components fall into the broad scope of Structural Health Monitoring (SHM).

- Transmission or PTO system - 5: Depending on the type of device considered, the transmission system may consist of a mechanical drive train (WTs, TTs and WECs), of a hydraulic circuit (WTs, TTs and WECs), or of air and water turbines (WECs).

- Generator - 6: Rotary generators are included in all WTs and TTs, and in most WEC concepts. WECs containing linear generators present specific needs in terms of CBM.

- Power electronics - 7: For any significant wind, tidal or wave power production, an electronic power converter is necessary to connect the $50-\mathrm{Hz}$, three-phase electrical network to a variable speed generator.

- Grid interface - 8: Electrical connections and transformers are necessary to collect power from individual devices, and to transmit it to shore through high-voltage connection.
- Control systems - 9 (not highlighted in Fig. 2): In addition to hydraulics, generators and PE, which play an important role in the device control but are handled separately in the present review, other control-related subsystems may be included. In the case of WTs, they include in particular sensors as well as braking, pitch and yaw systems. Higher-level control systems such as maximum power point tracking and other supervisory control are also active but they are not handled in this review.

\subsection{Data for CBM}

Regardless of the component monitored, an important point to consider is the data used for CBM and collected by the CM system. The situation is very different for WTs on the one hand, and TTs and WECs on the other hand.

Regarding WTs, one can distinguish two main types of data that can be used for CM: data from the standard supervisory control and data acquisition (SCADA) system, which typically give global indicators of the WT health, and data from CM-specific sensors, that can be used for more advanced diagnostics.

SCADA systems have progressively become a standardised practice in the wind industry, and they are now mandatory in any modern WT. They offer a very low sampling rate - values are 
generally averaged over a $10 \mathrm{~min}$ interval. The values monitored typically include active power output, wind speed, power factor, reactive power, phase currents, and temperatures of the nacelle, gearbox bearing, gearbox lubrication oil, generator winding and generator bearing [54]. SCADA systems are used to monitor the generated power and to confirm the operation of the WT. They can also be calibrated to transmit alarms to the wind farm operator. Generally speaking, SCADA systems were not originally designed for $\mathrm{CM}$, and therefore can only provide basic fault detection features.

Most commercially available CM systems, as well as new damage detection methods developed nowadays, are based on specific measurements (velocity, acceleration, strain, etc.) which are often not monitored by traditional SCADA systems, and require higher sampling rates than the SCADA system. Installation of the corresponding extra sensors on WTs is then necessary. As a result, the nature, number and location of the sensors that are used differ amongst commercially available CM systems, and there is currently no standardised practice $[26,55]$.

However, sophisticated analysis tools now make it possible to exploit better SCADA data in order to detect or predict failures in the system. Smarter use of SCADA data can then offer a cheap alternative to additional sensor networks, arising the interest of industrial players; furthermore some recent SCADA analysis tools can incorporate data from an installed CM system [56,57]. Conversely, many CM systems, although they are based on specific sensors, also incorporate relevant data from the SCADA system for a more reliable fault detection and diagnosis. Commerciallyavailable SCADA data analysis tools for WT health monitoring are reviewed in [57], while commercially-available CM systems are reviewed in [55].

In contrast, there is yet no such standardised system such as SCADA in the TT and WEC industries, rather, bespoke solutions are commonplace. A comprehensive review of measurement systems for WECs is found in [58]. The specific characteristics of WECs require that the traditional sensors used for $\mathrm{CM}$ be adapted accordingly $[59,60]$.

\section{Condition monitoring at the system level}

At the broadest level, failures can be detected and predicted by monitoring the performance of the whole device or farm, using data and system operating variables that are not primarily aimed at $\mathrm{CBM}$, thus requiring no additional sensor. Any performance degradation is indicative of a fault or developing damage.

As far as WTs are concerned, outputs from the SCADA system are generally used for this purpose: although these outputs may not be precise enough to allow for accurate damage detection, qualification and severity assessment, they can be sufficient to discern the presence of a fault, thus possibly triggering a more advanced diagnosis through purpose-specific CM system. Furthermore, methods based on SCADA data don't necessitate the use of additional sensors. The basic concept is to monitor the relationship between different data collected, by means of statistical analysis or artificial intelligence tools. In particular, the power curve, i.e. the relationship between wind speed and power output, indicates the overall health of the WT [61].

[57] provides a valuable survey of commercially available WT SCADA data analysis tools with a focus on health monitoring issues. Most of the 26 systems identified, whether they are based on statistical analysis or artificial intelligence, propose real-time reporting and analysis. Control and monitoring extend from individual WTs to wind farm cluster management systems gathering several, geographically-distant wind farms together. Some systems also feature component failure diagnostic capabilities. Recent products can be integrated with data from CM systems, thus allowing for a more comprehensive picture of the WT condition. The trend towards a more sophisticated use of SCADA data is particularly illustrated by the Wind Turbine Prognostics and Health Management demonstration platform, developed by the American Centre for Intelligence Maintenance Systems, which uses WT modelling to perform health monitoring and predictive maintenance in various operating conditions.

In contrast, the performance of TTs and WECs is above all monitored as part of the device development and testing process such as in $[62,63]$, so that generic approaches to detect faults based on the performance of the devices have not yet been developed. As a result, parts 3.1 to ?? are dedicated to WTs only.

\subsection{The challenges of power curve modelling}

Monitoring the performance of a WT or wind farm generally involves a comparison between the power output predicted by a model and the measured power output. Typically, the wind speed measured by the SCADA system is used as an input for the model to compute a predicted power, which is then compared to the actual, measured, produced power. Thus, the adequate modelling of the power curve - i.e. the relationship between the power output and inputs such as wind speed - is of critical importance for the accurate detection of abnormal WT behaviour. [64] provides a review of power curve modelling techniques, from simple piecewise or polynomial parametric models to advanced statistical methods such as the Copula model, and machine learning and artificial intelligence such as k-nearest neighbours, artificial neural networks (ANNs) or fuzzy logic.

As illustrated in Fig. 3, one of the difficulties encountered when monitoring the behaviour of a WT is the multi-regime nature of the power curve, which makes comparability of data from different periods challenging. This issue can be addressed by using only those data points that belong to a given part of the curve - generally the sloping part [66-68], and/or by splitting data into several [67] or many [66] data bins, e.g. depending on power output or

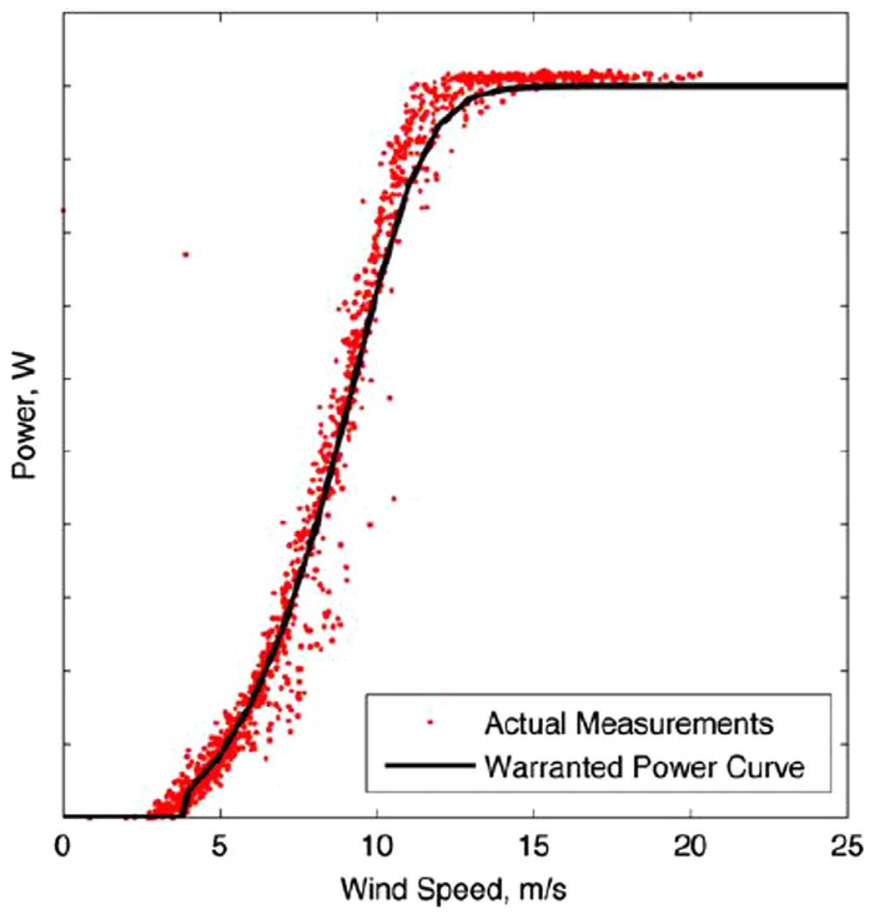

Fig. 3. Typical WT power curve [65]. 
wind speed. Another option is to use statistical or machinelearning techniques able to model multi-regime processes, for example the Gaussian Mixture model in [65] or clustering methods in $[69,70]$.

\subsection{Statistical relationships and machine learning tools}

Some authors, such as in $[67,66,69,71]$, study the statistical relationships between two or more sets of SCADA-recorded variables in normal and current conditions to detect abnormal operation of the WT. In [67], the covariance matrix eigenvalues of the two-dimensional dataset made of wind speed and power values are used as indicators of WT's normal or abnormal operation. In [69], three WT performance curves are monitored (power, rotor speed and blade pitch, all versus wind speed). Skewness and kurtosis of the obtained distribution are used to detect abnormal performance. In [71], the power curve of a whole wind farm is represented by a drift/diffusion model in which the drift coefficient is used as an indicator of the farm performance. Study [66] shows how SCADA data can be used to detect faults at the system level, but also for various WT sub-assemblies. The methodology proposed is based on finding appropriate correlation between pairs of SCADA data - depending on the component monitored. Correlation between any pair of data sets is depicted through a polynomial relationship whose coefficients are determined by LSE minimisation. The cumulative absolute difference between the polynomial correlation functions obtained on historical and current data is used as an indicator of abnormal condition. The comparison criterion is based on a wide range of operating conditions, i.e. along the whole curve of the correlation functions, thus making detection more robust. It is also worth noting that the authors propose a table suggesting possibly relevant correlations that could be explored to monitor various WT components.

In other studies $[72-77,65,70,68,61]$, advanced machine learning tools are used to model the complex, non-linear input-output relationships, before the WT performance is monitored, more often through residual analysis. In [65,73], several types of machinelearning tools are evaluated to model the performance of a WT. The deterioration index obtained from the Gaussian mixture model (GMM) in [65] seems particularly interesting, since it shows a gradual increase prior to all significant downtimes or maintenance events. Furthermore, the use of two or more clusters in GMM efficiently and intuitively models the multi-regime feature of the power curve. In [70], SCADA vibration data of the WT drive train and tower are used to monitor the WT health. Unsupervised data clustering through $\mathrm{k}$-means is explored, some clusters representing faulty states. Seven data-mining algorithms are also compared to model the WT behaviour and compute power residuals on which control-chart monitoring is performed, ANNs and ANN ensembles giving the most accurate results. [74] explores the potential of monitoring individual WTs and a whole wind farm with the use of SCADA data. ANNs and Gaussian Processes (GP) are first used to model the power curve of each individual WT of a 48WT wind farm. Then, the ability of each WT power curve to predict the behaviour of every other WT is represented as a $48 \times 48$ MSE matrix. Exceedingly high MSE values in the confusion matrix are expected to be a potential indicator of an abnormal situation in the WT or wind farm.

\subsection{Incorporation of relevant data and physical knowledge}

Wind speed and wind direction are not the only parameters governing the variations of the power output of a given WT, and this is probably why even sophisticated machine learning techniques can fail in accurately modelling the WT power curve, when only given wind speed as an input. Another important variable is

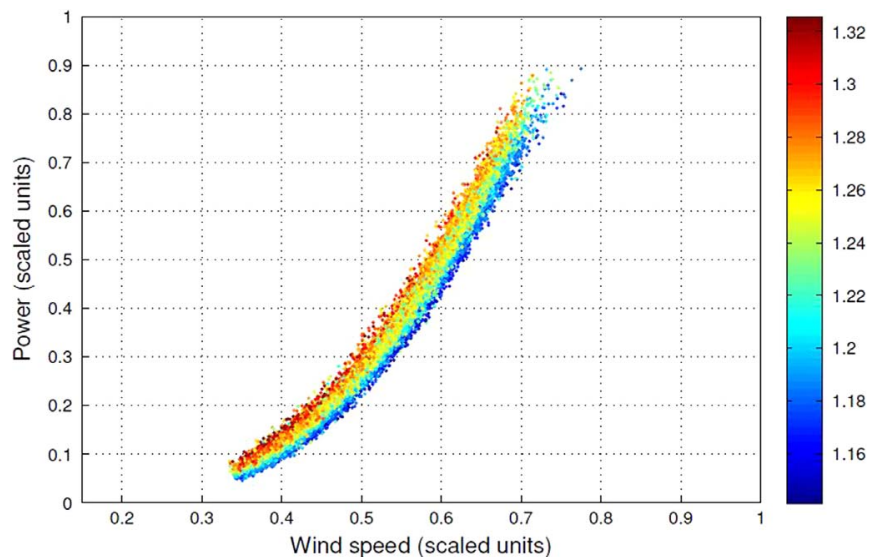

Fig. 4. Scatter plot of filtered ten-minute average wind speed and power measurements recorded for a WT over one year, where colour indicates the air density value [68].

air density, which is not included in most models proposed in the literature. Fig. 4 illustrates the gain of information that air density can provide for power output assessment [68].

Some authors have started to explicitly include air density as an additional parameter to wind speed and direction, with promising results $[68,61,75-79]$. In [68], the WT power production is modelled as a Gaussian process whose inputs are wind speed and air density. An interesting benefit of using a Gaussian process as a model is that the variance in the different regions of the input space can give information on the confidence of the prediction. [75] compares several WT power curve modelling approaches. The methods identified in the literature as the best performing cluster centre fuzzy logic, ANN and k-nearest neighbour models are all tested against each other, as well as against an additional method proposed by the authors using an adaptive neuro-fuzzy inference system (ANFIS) model. A comparison is made, first using wind speed only as an input, then adding air temperature and wind direction as inputs. Predictably, regardless of the method used, additional inputs reduce the variance of the prediction error and thus allow for earlier detection of abnormal performance. The results of all four methods are very similar and satisfactory as they all allow for a detection of abnormal WT performance. In [76] the ANFIS method is studied further by the same group of researchers and its incorporation into a performance monitoring algorithm is carried out. The algorithm is validated in [77] where its efficiency is shown on various malfunctions of WT sub-assemblies.

Finally, the idea of monitoring the performance of a WT by using data from other WTs is explored by several authors and can be very useful to check whether some data seem to be outliers, to replace missing data $[79,70,69]$ or more generally to improve diagnosis reliability [74].

In summary, it seems from the available literature that a number of techniques, whether they are based on statistical or physical models, or on machine learning and artificial intelligence, show very comparable performance. Furthermore, comparative studies are often based on one specific dataset, so that it seems risky to generalise conclusions with regards to which modelling method would outperform all the others and should then be favoured. But, regardless of the method chosen, a key factor in successfully monitoring WT performance is the incorporation of relevant variables, especially wind direction and air density.

In addition, working with purely "black box" models such as ANNs and other machine learning tools can be both complex, and not very informative. Even though modelling the behaviour of the entire WT through exact physical equations would be impossible or extremely difficult, incorporating some insight about the 
underlying physical processes, whenever it is available, is generally beneficial. [72], based on SCADA data, provides a good example of this trade-off, by combining a relatively simple modelling technique with a choice of parameters "informed" by knowledge about physical processes. Signal-trending and an ANN are compared with a method based on a physical model, and the latter is found to be the most reliable and informative. For a given component of the WT, a basic physical model determines the parameters governing the evolution of a monitored value (e.g. a model for a drive train component temperature can be derived from the energy balance of the component). The model then takes the form of a correlation between an output signal (e.g. temperature) and the input signals, the correlation order depending on the nature of the underlying physics. The model is then calibrated through datasets corresponding to normal conditions. It is worth noting that the more explanatory data are available and used in the model, the better the model performance. For example, not only temperature, but also coolant system and pitch motor duties, coolant pressure, as well as binary status variables of some WT subsystems, can be successfully added as inputs for the physical model. The method is tested on a wide validation test, showing early detection of incipient faults in most cases (from 1 month to 2 years before component failure).

In conclusion, as it doesn't necessitate the installation of sensors in addition to those of the SCADA system, monitoring the performance of WTs or wind farms seems to be a cheap and efficient way to provide various alarms [80], possibly triggering further investigation by CM systems specialised on specific subassemblies which will be the focus of Sections 4-9.

\subsection{Performance monitoring for TTs and WECS}

Unlike WTs, TTs and WECs are not equipped with standard measurement systems comparable to SCADA. However, it may be relevant to determine what the requirements would be in terms of input and output measurement in order to monitor the TT and WEC performance in real time.

Similarly to WTs, the response of TTs essentially depends on the velocity and direction of the incident flow and on water density. The TT power curve can then be used to predict the output power. However, in the case of TTs the incident flow should be measured or estimated upstream. In case the incident flow cannot be properly measured, it would have to be estimated through modelling of the coastal area, taking into account not only the predictable flow velocity due to tides, but also variations in the flow velocity induced by wave conditions over the area of interest. Finally, in some areas water density exhibits a significant variability which has to be taken into account in performance monitoring of TTs.

As far as WECs are concerned, the system input-output relationship is significantly more complex than it is for WTs and TTs.

- If the system input is considered to be the water surface elevation at every time, then the latter should be measured or estimated in real time. Predicting the power output then implies that the WEC hydrodynamic behaviour is properly modelled, including the effects of control if necessary.

- The system input could also be considered as the sea state (for example every hour), described by a wave spectrum, which should then be measured or estimated. In this case, the expected WEC output power could be derived from a power matrix, from an other parametric table, or from numerical simulations involving a suitable hydrodynamic model.

\section{Structural health monitoring}

WTs are increasingly tall machines subject to strong and intermittent loads. The condition of their structural components tower, nacelle, rotor and blades - is critical, since any damage to the structure threatens the integrity of the entire system [31]. WT tower, nacelle, rotor and blades then fall under the scope of SHM, which is defined by Farrar and Worden [81] as "the process of implementing a damage identification strategy for aerospace, civil and mechanical engineering infrastructure".

Structural damage can be caused $[31,32]$ by a gradual alteration of the material properties by fatigue, thermal stress, moisture absorption and corrosion, or by more sudden events such as strong wind gusts during storms, uneven ice accumulation on the blades, lightning strikes or even collisions with birds. Structural damage can also be the result of faulty manufacturing. The need for SHM is increased in the case of OWTs due to harsher operational conditions and remote location [82]. Finally, OWT foundations are subject to specific threats from the marine environment, in particular from wave-induced loading, corrosion, erosion and biofouling.

SHM is also relevant for TTs, since TT structural components, especially blades, seals and supporting structure, are under threat from the marine environment. Concerning WECs, the design of the primary interface for sea-keeping and device survivability has been the subject of most development and academic effort [44]. Structural integrity is indeed the most obvious concern, mainly due to the hydrodynamic loads induced by waves, and to biofouling. However, due to the early development stage of the tidal and wave energy industries, few published studies have been dedicated to SHM for WECs and TTs.

Reviews of the different sensing techniques that can be used for SHM of WTs [31-33,35] show that blades have received the most attention amongst the WT structural components, and that acoustic emission (AE) is the most widely used method in blade full-scale testing and certification, although strain measurement (SM) and vibration analysis (VA) are also common practice and many other detection techniques have been investigated.

However, authors [31-33,35] also highlight the fact that the implementation of damage detection methods via on-line SHM systems still faces strong operational, economic and environmental challenges. Data normalisation techniques must be developed to take into account the influence of varying operational conditions and strong ambient noise in the collected measurements. The damage detection technologies involved often require the installation of numerous sensors along with costly and bulky data-processing and interpretation units. The sensors themselves, especially those that are located on the blades, may require the development of energy-harvesting techniques [83-85] and are subject to failure. As a visible consequence of these difficulties, only 5 commercially-available WT SHM systems are identified in [55]. Three of these systems are based on accelerometers and the two others use fibre optic sensors. No commercialised SHM system appears to use AE. Finally, the challenges of on-line SHM implementation apply to TTs and WECs as well.

\subsection{Strain measurement}

SM can be used to monitor the health of WT structural components [86-88]. There are several sensing technologies $[32,31,89]$ : traditional strain gauges (electric transducers), optical fibre sensors, and strain-memory alloys (still at an early development stage). In [86,87], the authors investigate the use of a radial arrangement of strain sensors in the vicinity of the base weld joint of an onshore WT tower. The method proposed in [86] is based on the strain difference between two adjacent sensors in the array. [87] addresses the issue of the choice of the number of sensors, which is determined by the minimal crack size that must be 
detected. In [88], data from strain sensors and from the yaw mechanism are used with a Kalman filter to monitor changes in the WT tower neutral axis position, which can then be used to assess the presence of damage. The method [88] is simulated and validated on a finite-element model of the tower.

Strain sensors could be equally suitable for TTs and WECs [90$92,59]$, provided that they receive additional protection $[17,92]$.

In [90], it is shown that time-frequency (T-F) analysis of the axial thrust measured on the supporting structure of a TT can be a relevant tool for blade fault detection. The proposed method is able to reconstruct the instantaneous angular velocity of the blades and to provide a clear spectral representation of the thrust amplitude, which can be used as a basis to detect faulty blade conditions. Thrust measurement at the base of each blade can be used to detect individual blade offset [91].

SHM of WECs could be performed through the use of strain gauges combined with a model of the hydrodynamic response of the device, such as in [92]. Importantly, SHM requires that the normal device response is known for a given sea condition, which implies that a suitable hydrodynamic model is developed and the sea state is measured. A force transducer is incorporated into the measurement system proposed in [59] to monitor the force in the line which connects the floating buoy down to the linear generator (LG). A traditional strain gauge is used to measure the tensile force on the generator hull. Monitoring the forces experienced when the translator hits the upper end of the generator is of particular importance.

\subsection{Vibration analysis}

VA for SHM consists of monitoring the modal properties of the structure [32]. Changes in modal properties are interesting to monitor, not only because they are indicators of developing damage, but also because they can accelerate ageing of the structure; indeed, changes in modal properties may cause some lower modes of the structure to coincide with typical wave or gust frequencies, and higher modes to accord with the rotor higher harmonics, which could significantly reduce the expected lifetime of the structure [93].

In [94], the authors study data-reduction, pattern recognition and novelty detection techniques for damage diagnosis in a WT blade. The study is based on a laboratory experiment where a 9-m WT blade is excited at its resonance frequency until a crack becomes visible. The data come from two arrays of piezoelectric transducers. More precisely, as illustrated in Fig. 5, each array consists of several sensing transducers (S) arranged around an

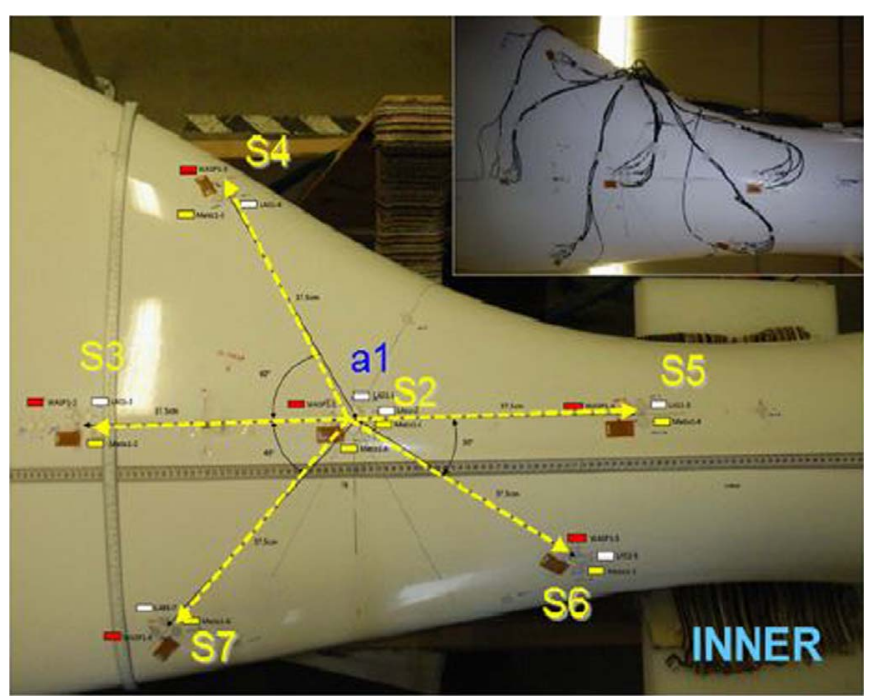

Fig. 5. Vibration sensor arrangement used in [94]. actuating transducer (a1), and records the high frequency response function of the blade at each sensor's location. Probabilistic principal component analysis is used to reduce the dimensionality of the data, and the features extracted are used as an input for two unsupervised machine learning methods: auto-associative ANN, and a novel approach based on a radial-basis function (RBF) network, both of which show an increase of the novelty detection index above the novelty detection threshold long before the crack became visible.

In [95], a numerical model of a $5 \mathrm{MW}$ OWT is implemented, and the presence of a shear web disbond on one of the blades is simulated. The study determines which dynamic variables could be used for disbond diagnosis. It is found that non-blade measurements (wind speed and direction, transverse nacelle acceleration) can be used to detect the presence of the shear web disbond, before blade measurements (span-wise tip acceleration, blade tip acceleration, blade root pitching moments) are used to confirm the presence and assess the severity of the disbond.

The challenges of using field measurements for modal analysis are illustrated in [93,96-98]. [93] reaches an important milestone towards continuous, on-line monitoring of the modal properties of an OWT tower. Vibrations of a mono-pile OWT tower and transition piece are measured on-line and recorded over a two-week period, as well as standard operational SCADA data. The data are then pre-processed and fed into state-of-the art modal analysis tools that have been automated, to successfully identify and track modal shapes, modal frequencies and damping ratios. During the measurement campaign, the WT was idling or in parked position. Further work is required to test the proposed method on an operating WT and to incorporate better non-vibration operational and environmental variables recorded by the SCADA system. [98] addresses the issue of the necessity of an excitation source to measure vibrational response; indeed, the proposed methods don't directly rely on the modal properties of the structure, but on the change of vibration propagation between two distant sensors, using ambient noise as an excitation source.

As for the tower and blades, modal analysis of OWT foundations can be performed [99], taking into account blade rotation, wind speed and direction, wave height and tide level; phenomena such as scour or seabed shift indeed have an effect on the structure natural frequency. In [100], the impact of biofouling on the dynamical response of OWTs is investigated.

Similarly to WTs with which TTs show strong structural analogies, numerical models could be used in conjunction with sensor data to detect TT structural damage and to estimate the RUL of structural components. The development of such models for TT blades is illustrated in [101-103], where fatigue analysis and life estimation of TT blades are investigated. In particular, the potential use of WT blade design and analysis tools for TT blades is explored in [102].

\subsection{Acoustic emission testing}

$\mathrm{AE}$ can be defined as "the phenomenon of transient elastic wave generation due to a rapid release of strain energy caused by a structural alteration in a solid material under mechanical or thermal stresses" [104]. AE signals are released in the very high frequency spectrum ( $>50 \mathrm{kHz}$ ), and therefore must be recorded by a transducer with a very high natural frequency. The advantage of $\mathrm{AE}$ analysis is that, unlike VA, it is sensitive to the growth of subsurface damage. In $\mathrm{AE}$ techniques, $\mathrm{AE}$ events are recorded, then characterised, e.g. by their amplitude, duration or frequency. Damage can be located by linear or triangular location, when arrays of sensors are used. AE testing is now widely used in laboratory fatigue-testing in the WT blade certification process [32,33,105].

The implementation of AE-based damage detection techniques on operating WTs presents specific challenges [105]. In particular, 
AE techniques require a high sampling rate (typically $>100 \mathrm{kHz}$ [25]) and a sensor location close to the damaged zones, which possibly implies a significant number of sensors and an expansive data processing and storage equipment [32]. No commercially available SHM system based on AE for on-line CM still exists [55].

However, the authors of [105] state that current technological advances allow for on-line AE implementation. After briefly tracing the development of AE techniques for WT blade SHM, they present results obtained from the first long-term, AE-based, online monitoring of a full-scale WT blade, through a system developed within the EU-funded research project "NIMO" (20092012). AE data are used in combination with WT operational data and strain values along the blade. Results open promising paths of investigation for application of advanced machine-learning techniques to classify $\mathrm{AE}$ signals. Emphasis is put on the essential, complementary use of non-AE operational data to help in classifying $\mathrm{AE}$ events, and on the need for advanced novelty detection techniques trained on abundant healthy-state data.

In the field of wave energy, acoustic analysis has been mainly performed with the aim of assessing the impact of WECs on marine life. However, it is proposed, in the scope of the ÆMORE project [106], that the experience gained in AE analysis of WECs could be used for damage detection of both structural and internal components. As in the case of WTs, one of the main challenges identified lies in the way to handle the large amount of high-frequency-sampled data, to identify $\mathrm{AE}$ events whose duration does not exceed several minutes. Nevertheless, compared to $\mathrm{AE}$ in a "dry" environment, underwater AE analysis presents significant advantages which could make the technique beneficial. In particular, the underwater ambient noise belongs to the low frequency range $(10 \mathrm{kHz})$, so that there should be less interference with the recording of $\mathrm{AE}$ events; furthermore sound propagation is better in water than in air, so that "sensors can be placed away from a WEC, where they can monitor multiple parts of a system at once [106]".

\subsection{Other methods, combination of measurements}

Alternatives to the well-established sensing methods described in parts 4.1-4.3 are experimented with WT SHM, but they are not yet technologically and economically ready for a full-scale on-line implementation. These alternatives include optical measurements [107-109], laser Doppler vibrometry [110], thermal imaging $[31,29,111]$, ultrasonic testing [31,112], electric conductance properties of carbon-fibre materials (electrical resistance and eddy-current) [31], and X-radioscopy [31,113]. In [114], a laboratory fatigue test is presented, in which many sensing techniques are compared to assess the effects of manufacturing-induced defects on a WT blade under laboratory controlled fatigue testing.

The authors would also like to mention advanced studies and projects in which combinations of measurements of different natures are proposed as successful SHM methods:

- A relevant combination of measurements is proposed in [115], where an aerodynamic sensitivity analysis on a numerical model of a $5 \mathrm{MW}$ WT is performed, in order to determine the measurements that are required for the detection of shear web disbond and rotor imbalance. The measurements retained include strain and torque measurements, such as blade root pitching moments and blade root axial force, acceleration measurements such as blade tip and root accelerations, as well as generator power and wind speed.

- The EU-funded research and development project REMO [116], aims at improving the availability of TTs to $96 \%$ and reducing maintenance costs by $50 \%$, through a CM system sending data onshore via a wireless transmission system. The REMO system is able to perform SHM of the TT, including biofouling on the blades, through $\mathrm{AE}$ (for the high frequency spectrum) and VA (for the low and medium frequency spectrum). Data processing tools, including Fourier transforms and signal averaging techniques (rootmeansquare voltage, peak-to-peak average voltage), are developed in combination with pattern recognition techniques. The AE sensors are waterproofed; furthermore, underwater tests show that faults can be detected in spite of the effects of the marine underwater environment, such as increased background noise and higher stress on components. The proposed system is said to be flexible enough to be applicable to some WECs.

Finally, SHM for WECs may be more challenging than for WTs and TTs. Admittedly, some WEC structural components could lend themselves to damage accumulation models, thus allowing for a probabilistic estimation of the device RUL. In [117], it is shown that methods to evaluate the probabilistic distribution of offshore structure lifetime have long been investigated, and can be adapted to the field of wave energy conversion. The component modelled is a hydraulic ram - which transfers the energy of the primary interface to the hydraulic system. A damage accumulation model depending on the significant wave height is used in combination with the probabilistic distribution of future sea states. In a real-world application, the RUL estimate could be updated depending on actual, recorded sea states. However, such an approach requires that peak loads on the monitored components can be derived from the knowledge of the operating conditions, which may involve the appropriate modelling of the WEC behaviour in various sea states. As detailed in [118], modelling the WEC response in extreme sea states is particularly challenging, since it involves highly nonlinear and localised events such as slamming. Methods relying on potential flow, high-fidelity CFD, or physical modelling through scaled models, are reviewed. In extreme sea states, many WECs are likely to enter into a survival configuration, requiring specific modelling of the loads.

\section{Transmission system}

\subsection{Mechanical drive trains}

Mechanical, rotary drive trains are present in the design of the vast majority of current WTs and TTs. Some WEC concepts also include rotating drive trains including gears and bearings, such as SeaRay [53] and the CorPower wave energy point absorber [52]. Even though drive train components remain similar in nature, the load variability differs across WTs, TTs and WECs, thus making $\mathrm{CBM}$ requirements specific.

Drive train failures are a major cause of WT downtime, especially OWTs [119]. In particular, the gearbox of indirect-drive WTs is by far the greatest concern for wind farm operators [25,26], because of its high cost, the highest downtime per failure amongst all WT subcomponents, and because it is subject to premature failure [120] due to the strong wind variability. The most common WT gearbox faults are summarised in [28].

The methods applied for drive train health assessment fall under the scope of rotating machinery diagnostics and prognostics, which are present in many industrial fields. In the present subsection, the available literature is classified according to the type of measurements on which diagnostic techniques are based, the most popular methods being VA and oil analysis (OA). A brief overview of studies dedicated to rotating machinery prognostics is then presented.

\subsubsection{Condition monitoring methods}

5.1.1.1. Vibration analysis. VA is by far the most popular method employed for the CM of WT drive trains, in particular gearboxes. $27 \mathrm{CM}$ systems out of 36 identified in [55] are primarily based on 


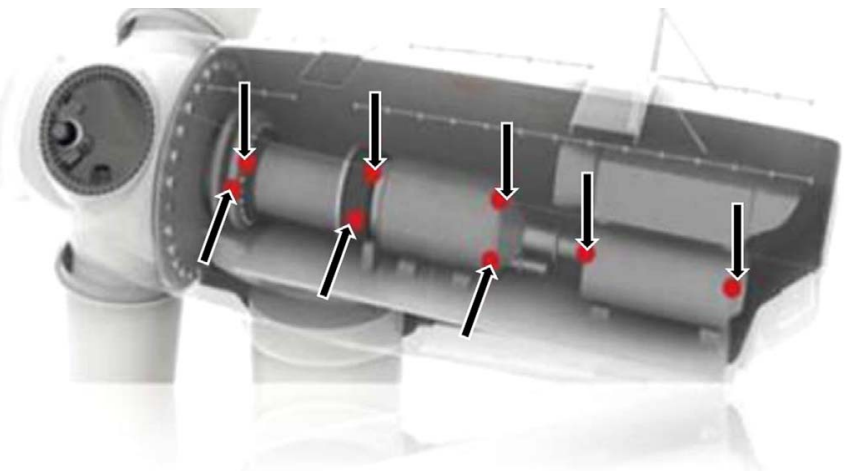

Fig. 6. Typical location of accelerometers in a WT drive train [123].

drive train VA. VA had already been widely developed and implemented in industrial sectors using conventional rotating machinery, allowing for significant technology transfer. However, the highly-varying load and harsh environment in which WTs operate bring specific challenges.

Vibration measurements are obtained through position transducers, velocity sensors or accelerometers [121] covering frequencies from $1 \mathrm{~Hz}$ to several dozen $\mathrm{kHz}[54,122]$ in strategic points of the drive train, such as in Fig. 6.

Vibration signals must be processed in order to extract frequency components or other features that are relevant to health estimation and prediction. A clear presentation of the existing signal processing techniques used for WT VA can be found in [35]. Classic VA techniques can be based on quantities directly computed from time-domain signals [122,124-126], or on frequencydomain analysis $[104,127,128]$. The main drawback of classic signal processing methods is that they must be used on a stationary signal to provide coherent information, which is not adapted to the highly variable nature of the WT operational conditions [129]. T-F analysis techniques are better able to deal with non-stationary input signals. Most T-F analysis techniques can be categorised into short-term Fourier Transforms (STFT) [130], Wavelet Transforms [131-133], Cohen Class Distributions (CCD) and Empirical Mode Decomposition (EMD) [134-141]. T-F methods are compared in [142] in terms of computational cost, resolution and readability of results. It is shown that the preferable method may, above all, depend on the specific user's constraints. However, most commercially available systems described in study [55] use classic signal processing techniques to extract relevant information.

Once the vibration signal is processed, the subcomponent health can be assessed in different ways. In recent studies, T-Fprocessed data are analysed through advanced machine learning techniques, such as ANN or support vector machines (SVM). In [143], the coefficients obtained from a discrete wavelet transform (DWT) are fed into an ANN to classify WT bearing vibration data into five possible healthy or damaged conditions. Studies [144,145] show that SVM algorithms have a better generalisation capability than ANNs, as well as a shorter learning time in some cases. In [146-148], different SVM algorithms are used to classify features extracted from WT gearbox vibration.

Nevertheless, as pointed out in [149], the aforementioned VA methods can be demanding in terms of computational time or historical data requirement. This is why some authors propose simpler and more pragmatic methods to circumvent the problem of non-stationarity without resorting to T-F analysis and machine learning. For example, data can be sampled only when predefined operational conditions are reached [26]. In [150], the proposed gear fault indicator, namely Side Band Power Factor (SBPF), relies on the power spectrum amplitude of the second mesh frequency harmonic and its side bands. The spectrum, obtained through a simple FFT, is normalised to the shaft rotational frequency, so that cyclic events synchronised with the shaft rotation appear at a fixed position in the spectrum, even in varying-speed conditions. Thus, only load variability must be taken into account.

Finally, the concern of computational efficiency has also influenced some work in the field of data processing and analysis for TTs. Although it lacks field data, [151] provides a very valuable investigation of vibration data processing and analysis tools that may be applicable to TTs. The performance of VA techniques, artificial intelligence classification tools and post-processing techniques are assessed, with respect to the specific constraints posed by the application to TT monitoring: developed algorithms must allow for small-scale, on-site computing solutions to process and analyse the high-frequency data from vibration sensors, while limiting the amount of data to be transmitted onshore. A similar philosophy shows through studies [152-155], where the techniques considered tend to reduce the amount of data to be processed and improve the performance of subsequent diagnosis tools based on machine learning. Feature selection is applied to a wavelet transform of vibration data in [153]. Studies [152,154,155] explore data fusion at different levels - from the fusion of data from different sensors to the fusion of wavelet transform features.

5.1.1.2. Oil analysis. Lubricant oil is used to ensure optimal operation of WT gearboxes and can be analysed in order to assess the quality and performance of the lubricant itself (oil PM), or in order to characterise the degradation of rotating parts through the detection of wear particles suspended in oil. In some reviews OA is still considered as being too expensive for implementation on operating WTs $[23,25]$. Furthermore [25] points out that OA can only be used in closed-loop oil lubrication systems.

However, in [55], 6 of the commercially available CM systems reported use oil quality monitoring as a complement to VA, and 4 systems are solely designed to monitor oil quality. [34] is a very interesting and comprehensive review of OA techniques, discussing their applicability to WT gearbox monitoring. Taking into account costs and adaptability into miniaturised sensor systems, the most promising technologies are identified, both for oil PM and for degradation assessment of mechanical parts through wear particle detection. The main idea promoted is that the most realistic solution to evaluate oil parameters is probably not to rely on very precise (thus possibly big and costly) sensors, but rather to combine several cheaper sensors measuring different effects, provided that relevant statistical methods are used to process and analyse the data collected.

The recent interest in WT gearbox oil $\mathrm{CM}$ is illustrated in $[156,157]$. A laboratory set-up designed to test different sensors for on-line oil monitoring in a WT gearbox is presented in [156]. The effects of extreme vibration and ambient temperature levels are investigated. [157] provides an example of an experimental integrated system using several sensing technologies: the System for On-line Oil Analysis (SOOA) is able to monitor physical and chemical oil properties as well as the number, size and mass of wear particles. Damage detection is based on a transient identification algorithm, as illustrated in Fig. 7.

Finally, oil debris measurement has such a direct relationship with the level of damage that it can serve as a base for state prediction methods such as in [158], where Unscented Kalman Filter is used for current system state estimation, and Particle Filtering for RUL estimation of a spiral bevel gear.

5.1.1.3. Other methods. Electrical analysis (EA), i.e. the analysis of current or power in the generator, presents a cheap alternative to direct measurement of vibration or torque inside the gearbox [159-166]. Indeed, mechanical faults in a WT drive train can result in changes in the mechanical torque applied to the generator by 


\begin{tabular}{llll}
\hline \multirow{2}{*}{ Fault } & \multicolumn{3}{c}{ Oil property } \\
\cline { 2 - 4 } & Temperature & $\begin{array}{c}\text { Rel. water } \\
\text { content }\end{array}$ & $\begin{array}{c}\text { Rel. dielectric } \\
\text { constant }\end{array}$ \\
\hline $\begin{array}{l}\text { Water } \\
\text { Contamination/ } \\
\text { Condensation }\end{array}$ & (No influence) & & \\
\hline $\begin{array}{l}\text { Chemical } \\
\text { contamination/ }\end{array}$ & (No influence) & (No influence) & \\
Oil aging & & & \\
\hline $\begin{array}{l}\text { Excessive wear/ } \\
\text { Pitting }\end{array}$ & (No influence) & (No influence) & (No influence) \\
\hline $\begin{array}{l}\text { Particle } \\
\text { contamination }\end{array}$ & (No influence) & (No influence) & (No influence) \\
\hline
\end{tabular}

Fig. 7. Two specific gearbox faults and indicative oil properties - reproduced from [157].

the prime mover, and thus to the power and current signal, which can be monitored without requiring any expensive additional sensor. However, it is unlikely that EA can obviate the need for other techniques, since its range of detection abilities does not cover all potential failure modes [165,167].

Other, less popular methods for mechanical drive train $\mathrm{CM}$ include the Shock-Pulse Method (SPM) [104,168], AE analysis $[55,169]$ and torque measurement $[119,164]$.

5.1.1.4. Combination of various data. Instead of being mainly based on one specific measurement technique, some fault diagnosis techniques use a combination of data of various natures [170$172,26,72]$, including SCADA data which offer the advantage of requiring no additional sensors. In particular, although it is not a precise enough stand-alone indicator for a real-time CM system [173], temperature can be usefully exploited along with other data to enhance diagnosis reliability.

In an aforementioned study [72] (see Section 3), a physical model-based method is applied, amongst others, to monitor the temperature of several gearbox bearings as well as the main bearing temperature, using as inputs a variety of SCADA data combinations - depending on the component considered. The results of the validation test showed that an abnormal increase of the deviation from the modelled temperature could be detected several months prior to failure.

The relationship between SCADA data in fault-free conditions can be modelled through advanced machine-learning techniques $[170,171]$. In [170], SCADA data (main bearing temperature, main shaft RPM, hydraulic brake temperature and pressure, and blade pitch position) are used to estimate the RUL of a WT main bearing. Sparse Bayesian learning is used to model the relationship between the data in fault-free conditions, in order to generate a residual between modelled and measured bearing temperatures. Particle filtering is used to build a probabilistic RUL estimation. An approach based on ANNs is proposed in [171] for fault detection of WT gearbox bearings. An ANN is used to model the temperatures of the five gearbox bearings under normal conditions, using other relevant SCADA data as inputs. Anomalies are detected through Mahalanobis distance. It is shown, in the case studies presented, that the proposed method provides indication of incipient damage almost a week before a CM system based on VA.

Other examples of gearbox CM techniques solely based on SCADA data are reviewed in [172]. It is demonstrated in [56] that SCADA data (such as power output and oil and gearbox temperature) and $\mathrm{CM}$ data (vibration, oil particle counts) show a good complementarity, the preferable data depending on the fault considered.

AE can be a useful complement to VA, since using both techniques together enables coverage of the whole range of vibration frequencies that can possibly be generated by rotating equipment in operation. For example, in [169], the combined vibration and $\mathrm{AE}$ signature of a healthy WT gearbox and generator is determined. It is also the case in the TT-dedicated REMO system (see Section 4.4) which includes the internal rotating machinery.

\subsubsection{Prognosis tools}

General reviews of rotating machinery prognostics methods can be found in $[174,175,149]$. [149] in particular, focuses on prognostic techniques that can be applied to non-linear and non-stationary rotating systems (such as WTs, TTs and WECs). The techniques discussed are mainly data-driven approaches. Extended Kalman filtering, SVM and Fuzzy-logic are identified as the less demanding methods in terms of data requirements, which represents a significant benefit considering the fact that it is often challenging to obtain a large amount of data, especially for TTs and WECs. In [175], a methodology to select the most suitable prognostics and health management tool, depending on the considered application is presented.

A few model-based prognostic methods for TT and WEC gearboxes can be found. [42,176] are dedicated to predictive maintenance of TT gearboxes. A physical fatigue load model is used in combination with the predicted load spectrum that the TT is expected to experience. Miner's rule (the simplest damage accumulation model) is used to sum the damage accumulated under the different load conditions. In a real-time application, the proposed method could update its RUL estimation through measurement of speed and torque actually experienced and by refined load forecasting. In [53], a damage accumulation model of the main drive shaft bearing of the SeaRay device, under different sea conditions, is studied as a prerequisite for life-extending control. A standard RUL estimation equation for ball bearings is used, in combination with Miner's rule to sum the fatigue load over time. However, as stated earlier in Section 4.4, this type of approach would require very reliable modelling of the WEC hydrodynamics, including behaviour in extreme sea states.

\subsection{Hydraulic transmission systems}

In hydrostatic transmission WTs, cylinders displace pressurised oil in a hydraulic circuit [50]. Amongst other advantages, the hydraulic system is lighter and cheaper than a gearbox; furthermore, it allows for a mechanical decoupling of the rotor from the generator [177], which allows the generator to operate in less demanding conditions. The economical benefits of a hydrostatic transmission system are studied in [178]. However, the hydrostatic transmission efficiency is lower than the efficiency of a gearbox, and pressurised oil represents a threat to the environment in the case of leakage [50]. Motivated by the current lack of operational data, [179] proposes a methodology to evaluate availability and failure rates for hydraulic drive trains.

A typical WEC hydraulic circuit is shown in Fig. 8. Hydraulic circuits in WECs present specific challenges [44]. In particular, fluid containment and sealing may be issues, both to ensure the normal operation of the WEC and to prevent any leakage of fluid that could threaten the surrounding environment. Furthermore, to ensure efficient operation of the WEC, the hydraulic system must be compatible with complex control strategies, which implies the 


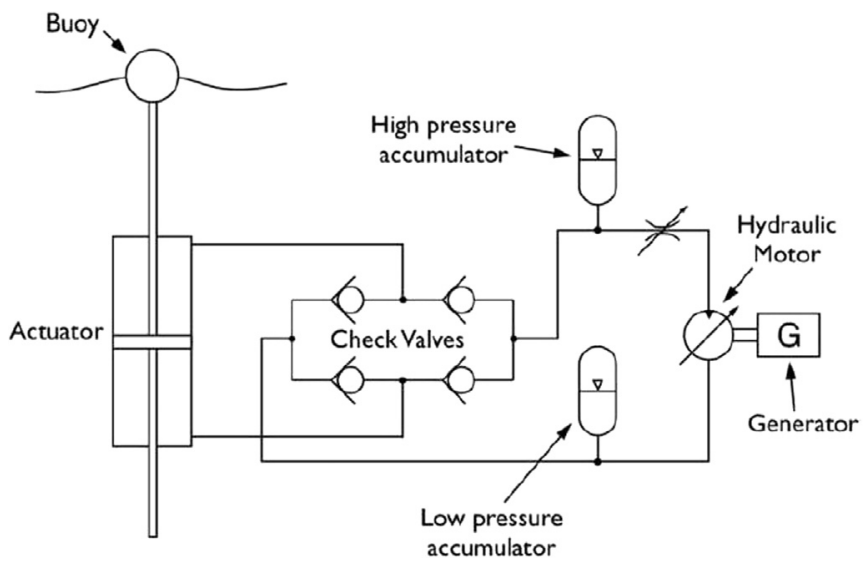

Fig. 8. Typical WEC hydraulic system [44].

development of innovative hydraulic system concepts such as Digital Displacement ${ }^{\circledR}$, as in the wind industry. From the point of view of CBM, there are two consequences. Firstly, more complexity also implies more possible failure causes and a more difficult fault detection and identification, and secondly, the absence of historical failure data for these new systems and applications could slow down the development of data-based techniques.

The fact that hydraulic conversion systems are being developed both for the WT, TT and WEC industries would justify significant research efforts to develop efficient fault-detection and predictive maintenance systems for hydraulic circuits in these applications. Appropriate $\mathrm{CM}$ techniques would, of course, be very different from those used for rotary drive trains, since VA and OA would be of little use. Due to wear or damage of the seal, internal and external leakage should receive significant attention, such as in other applications. CM techniques can be based on a physical model combined with Kalman filters and adaptive observers to handle parametric uncertainties [180-182]. As reviewed in [183], some authors preferably adopt a data-driven approach using signal-processing techniques such as the Fourier transform, wavelet analysis and EMD. In [184], cross-correlation analysis of the pressure signals of the two chambers of an electro-hydraulic actuator shows the ability to detect hydraulic actuator internal leakage with a high sensitivity.

\subsection{Air turbines}

Air turbines are used in oscillating water columns to convert the air flow into mechanical energy. The most common air turbine type for OWCs is the Wells turbine [44], although other designs including Dennis-Auld air turbines or impulse air turbines are also reported [51]. According to [185], the simple concept of OWCs makes them relatively reliable and easy to maintain; however that statement needs to be confirmed by long-term experience of OWCs in operation.

\subsection{Hydraulic turbines}

Hydraulic turbines can be used in some WEC concepts. The common turbine types for overtopping WECs are the Kaplan and Francis turbines. Pelton turbines are suitable for pumping systems such as those used in wave surge converters [51]. All these turbines are subjected to threats from the incoming water [44], in particular erosion from abrasive particles and from cavitation.

Experience from the wind industry, from ship propellers [186] or from the hydroelectric industry $[187,188]$ can be useful for turbine damage detection in overtopping WECs. In [187], cavitation-induced vibrations of a Kaplan turbine are monitored through high frequency accelerometers. AE could also be used to this end, e.g. for Kaplan and Francis turbines [188]. However, further work is probably necessary to adapt such methods to WECs, given the difference between large turbines of the conventional hydroelectric industry and the much smaller scale of WEC turbines. Investigated in the fields of wind energy (4.4) and ship propellers [186], laser Doppler vibrometry can be used as an SHM tool to monitor the dynamic response of rotating structures, although it is still far from being cost-effective.

\section{Generator}

\subsection{Rotary generators}

WT generators are susceptible to both electrical and mechanical faults. Today's most popular WT concepts are variable speed WTs based on doubly-fed induction generators (DFIGs), especially wound-rotor induction generators (WRIGs). Permanent-magnet synchronous generators (PMSGs) are also attracting more and more interest in the scope of direct-drive WTs. In short, generator types which must receive the most attention for WT design are induction generators (IGs) and PMSGs [189].

WT generator CBM falls under the wider scope of CBM for electrical machine, which include electrical generators and motors and have already attracted a lot of research, since electrical machines are widespread in a variety of sectors and their importance is critical in many industrial applications. Reviews of rotating electrical machine CM techniques can be found in [189-191,30]. Electrical machine CM methods rely on various measurements such as current, voltage, magnetic field or vibration [191]. The most widespread method is the Machine Current Signature Analysis (MCSA) which uses the stator current spectrum.

However, most of the traditional methods are only efficient under constant load and speed conditions. Recent industrial applications, such as WTs and electrical vehicles, necessitate tools that are able to overcome the specific challenges of varying operating conditions, which are the subject of [30]. The general principle of any diagnosis technique is to detect the presence of specific fault components in the signal and assess their energetic density which gives an indication of the fault severity. Compared to frequency-domain, time-domain and slip-frequency [192] analysis, T-F analysis is found to be a more suitable and popular diagnosis option to deal with non-stationary operating conditions.

Wavelet analysis is used to track and monitor fault-related components in the power output of a WT generator in $[193,194]$ and in the rotor voltage in [195]. Study [196] describes a continuous, adaptive T-F transform which enables identification of fault components in WT IG signals. Based on the theoretical T-F evolution of the fault components under a predefined speed transient pattern, the proposed T-F transform is calibrated to provide a T-F resolution adapted to the evolution of the signal of interest. The proposed methodology is successfully applied to detect several components related to stator and rotor asymmetries. It circumvents both the lack of flexibility in the T-F resolution of STFT and DWT, as well as the cross terms that appear in the WVD. However, the proposed T-F transform is based on the a priori knowledge of a specific predefined transient. Finally, based on computational cost, T-F resolution, and readability of the results, various T-F methods are compared in [142] for WT generator fault detection.

Finally, some authors prefer to examine alternative electrical signals sensitive to specific failures, rather than using complex signal processing techniques [197-199].

In spite of the numerous innovative techniques proposed in the literature, for now the methods used in the wind industry are more basic than those described in the present subsection [55]. The commercial systems that include generator fault detection 
only use temperature or generator bearing vibration. CMSWind, under development, is the only reported system using electrical signals. It will combine motor current signature analysis, operational modal analysis and AE techniques.

As far as TTs and WECs are concerned, to date most efforts have been made on the choice, design and modelling of the generator topology. Little or no published studies were found on the CBM of rotary generators specifically used in TTs and WECs. However, most generator types considered - DFIGs and PMSGs - are similar to those used in modern WTs [200,44,51].

The applicability of the methods reviewed in the present subsection to TTs and WECs depend on the specific TT or WEC design. In some cases, for example when the generator is decoupled from the wave motion through a hydraulic motor, and in the case of TTs, the variability of the generator operating conditions may be less significant than in WTs, thus making damage detection methods easier to develop. In some other WEC designs, for example with a mechanical drive train, it could be expected that the variability of the generator load and speed will be significant and have different characteristics compared to their WT equivalents.

\subsection{Linear generator}

In spite of their relatively high price, the development of new magnetic materials and the reduced costs of PE have made LGs a suitable solution for a direct conversion of WEC reciprocating motion into electricity [44]. Although LGs obviate the need for any intermediate equipment between the primary interface and power generation, they require sophisticated PEs to convert the initial electrical signal, which has a varying frequency and amplitude, into a sinusoidal pattern compatible with grid connection requirements.

Specific aspects related to WEC LG monitoring are illustrated in [59]. Critical quantities to monitor for CBM of linear generators could include [59] electrical quantities, generator temperature, water level inside the generator, translator position, as well as the forces experienced when the translator hits the endstops, since those forces could be of particular importance in damage accumulation.

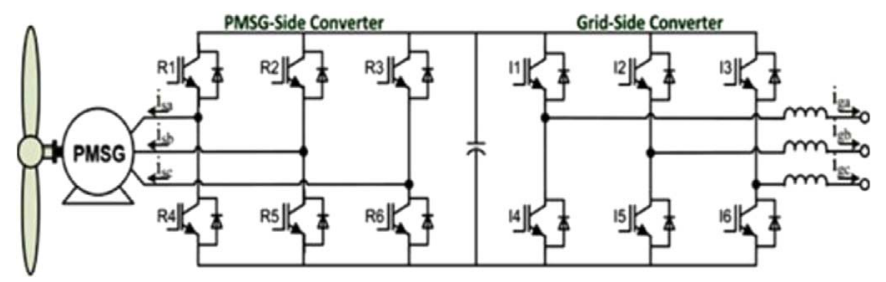

Fig. 9. Typical structure of a PMSG WT converter [201].
Given the significant number of WEC concepts involving a linear generator, CBM for linear generators deserves a specific research effort.

\section{Power electronics}

In today's multi-MW variable speed WTs, a power converter is necessary to connect the $50-\mathrm{Hz}$, three-phase electrical network to the generator [202]. Except for hydraulic-drive WTs, with a synchronous generator directly connected to the grid,"all WTs include a PE stage to control the power flow and manipulate the rotor speed" [203]. The scale, type and functions of the power converter depend on the WT design, especially the type of generator, as detailed in [49]. The power converter is generally made of two AC/ DC converters connected in a back-to-back arrangement (Fig. 1).

As explained in [49], PE used in WTs are rising in complexity, particularly driven by the need to handle more power and by increasingly demanding network connection requirements. As a consequence, PE may represent a higher share of WT costs. Besides, estimates from onshore wind statistics show that PE converters may account for approximately $13 \%$ of the failures and $18 \%$ of the WT downtime [204]. With this in mind, CBM systems, able to prevent major PE converter failures and to plan a wise scheduling of maintenance, are identified as a significant potential WT cost reduction factor. This is especially true for OWTs since downtime per failure will generally be higher than onshore because of the limited OWT accessibility [203], and also because stress factors such as vibration and humidity [49] are more significant in offshore locations. According to [203], the cost of a PE CM system would not exceed $£ 5000$ per OWT, while the average cost of PE-related failures would at least amount to $£ 47,000$ per OWT, per year.

The challenges linked with PE converters in TTs and WECs will be similar to those encountered in the wind industry; the power converter configurations will also depend on the generator topology chosen $[200,205,51]$, and reliable PE, able to deliver a good power quality [205,206], are likely to be a crucial component for full-scale TT and WEC deployment.

The basic design of WT PE converters, depicted in Fig. 9, remains similar regardless of the generator type [203]. Each of the two voltage-source converters (VSC) consists of six insulated gate bipolar transistor (IGBT) semiconductor PE devices, each with a diode in antiparallel. Each VSC is packaged in the form of a PE module. The two main IGBT packaging types are represented in Fig. 10.

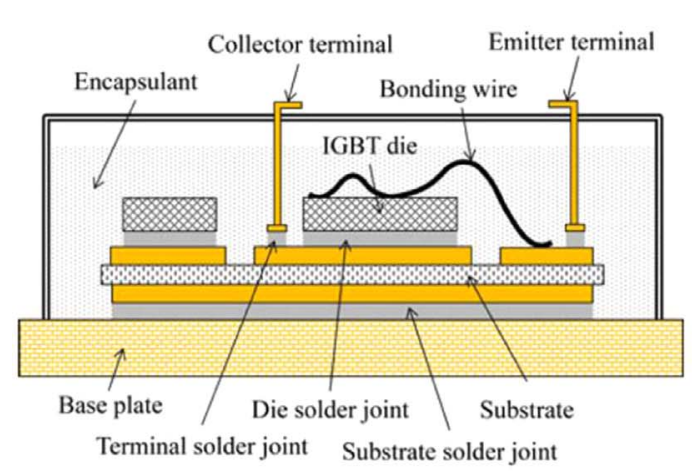

(a)

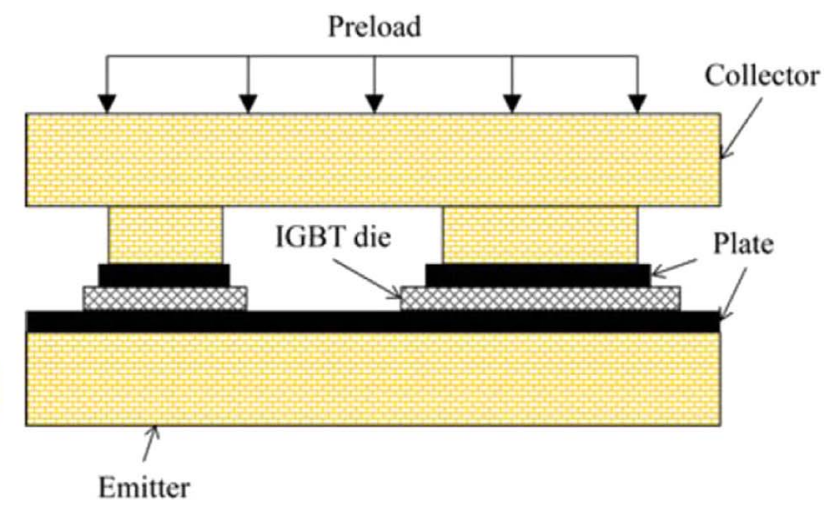

(b)

Fig. 10. Cross-sectional view of typical wire bond (a) and press-pack (b) IGBT modules [212]. 


\subsection{Fault detection at the PE converter level}

At the broadest level, most failures in PE modules are due to electrolytic filtering capacitor faults and PE semiconductor device faults [189]. The latter can be classified as short-circuit or opencircuit faults $[207,208,189]$.

IGBT open-circuit faults degrade the performance of the system but do not generally cause shut-down [207], and therefore can remain undetected for a long time [208]. Open-circuit diagnostic methods have then often been developed with a view to faulttolerant control [209]. Open-circuit fault detection methods are reviewed and discussed in $[207,209,189]$. Although methods based on the Park's vector [209] have received the most attention [208], many alternatives have also been explored [209]. Most methods investigated are non-invasive and do not require additional sensors. A recent example of an observer-based method for multiple IGBT open-circuit fault detection in a WT PMSG drive can be found in [201].

In contrast, as explained in [207], short-circuit IGBT faults very rapidly evolve to catastrophic failures. As a consequence, most short-circuit fault detection methods are implemented in hardware as protection schemes.

\section{2. $C M$ of PE devices}

Several critical or emerging industrial applications (such as automotive, aerospace, wind and $\mathrm{PV}$ industries) now require more reliable PE devices, which is driving research toward a better understanding of physics of failure and to the development of intelligent control and monitoring systems at the PE device level $[204,210]$. Unlike methods which are the subject of Section 7.1, the $\mathrm{CM}$ of PE devices demands that the gradual alteration of PE devices be assessed and predicted. Physics of failure play a key role, both in PE reliability assessment and in PE diagnosis and prognosis.

\subsubsection{Diagnostics and prognostics for faults related to thermo-} mechanical stress

Most common PE device failures appear when the packaging material is damaged under the effect of thermomechanical fatigue stress [211], which lends itself to physical modelling.

A very interesting and recent review of $\mathrm{CM}$ and prognostic techniques for IGBT PE can be found in [212]. To estimate the RUL of IGBT devices, although purely data-driven approaches using particle filtering are reported in [212], model-based methods are more suitable for applications such as WTs, where operating conditions are highly non-stationary [211]. In the latter case, three main challenges are identified in [212] for a reliable, real-time, RUL estimation:

- The environmental and operating conditions must be converted into thermomechanical stress through methods allowing for fast computation, e.g. using pre-filled look-up tables, or by modelling simple, linear relationships.

- Methods, such as the rainflow counting algorithm, are used to convert the complex load cycling history into sequences of identical cycles, in order to be able to use the results of laboratory fatigue tests, which are often provided by manufacturers.

- Finally damage accumulation has to be estimated by methods such as linear damage accumulation models, which typically combine the Coffin-Manson equation and Miner's rule.

These three steps are illustrated in recent studies dedicated to WT PE life estimation or reliability assessment. In [213], a cumulative damage estimation methodology is proposed to estimate the RUL of WT PE components. [214] compares the reliability of identicallyrated onshore and offshore WT PE, while [215,216] respectively evaluate the effects of wind speed and WT control on the estimated lifetime consumption rate.

However, PE device CM techniques are still at a very early development stage. In particular, experiments in laboratories and on actual WTs would be necessary to validate the methods currently investigated.

\subsubsection{Diagnostics and prognostics for other types of faults}

It should be noted that the typical PE failure causes in WTs are not yet fully understood and might not be the same as in other applications. Findings presented in [217] suggest that the usual faults related to thermomechanical stress, such as solder degradation and bond-wire damage, could be of less importance in WTs, compared to electrical overstress and converter protection against environmental threats such as salt, condensation and insects, which would mean that CBM approaches currently developed for a wide range of applications should be complemented with more specific methods for a successful adaptation to OWTs.

Since it is shown in $[215,216]$ that the control strategy and the operating conditions have a strong influence on the lifetime of PE components, specific work is needed to adapt prognosis techniques to the specific case of TTs and WECs.

\section{Grid interface}

There are many possible electrical configurations for wind, wave and tidal farms $[11,51]$. In general, devices are connected to the collection grid (individually or collectively) through low-voltage transformers. The voltage of the collection grid is then typically stepped-up in an offshore substation by a high-voltage transformer, in order to transmit power to the shore through a high-voltage transmission line, which can be AC or DC depending on the distance to be covered [11]. High- and low-voltage step-up transformers, as well as grounding transformers [218], are critical components. As far as WTs are concerned, the low-voltage step-up transformers of individual turbines are reported to fail prematurely, due to the variable load of the WTs resulting in frequent thermal cycling, and to the harmonic content of the WT power output [219,220].

The condition monitoring and predictive maintenance of power transformers are common practice, given their importance in electrical transmission and distribution systems. The corresponding techniques are reviewed in [221] and include, for instance, dissolved gas analysis, temperature monitoring, partial discharge analysis and frequency response analysis.

\section{Control subsystems}

This section is dedicated to control-specific subsystems found in WTs. TT and WEC designs also include their own control subsystems, but they are still too diverse to lend themselves to a detailed analysis of CBM issues. The relevance of pitch and yaw systems for TTs is discussed in [39,222,223].

A didactic overview of current approaches in WT control can be found in [224]. The general structure of a control system for modern WT concepts is shown in [49] and involves many components, including the generator and PE. PE play a crucial role in the WT control system, from basic features such as current and voltage control and grid synchronisation to more advanced features, including power maximisation and limitation, fault ridethrough abilities and various grid-supporting functions [49]. The present subsection is dedicated to other subsystems that are 
specific to WT control: the blade pitch system, the yaw system, and the mechanical brakes. The available literature on corresponding CBM is still limited.

\subsection{Mechanical brake}

A mechanical brake is generally installed on the high-speed shaft for over-speed control and emergency stop of the WT. CBM of mechanical braking system (e.g. hydraulic system and motor, brake disc and calliper) is still relatively undeveloped [225]. It is proposed, in [226], that faults in the hydraulic system and in the three-phase motor can be diagnosed through motor current signature analysis, while fault diagnosis in the brake disc and calliper could be performed by means of non-contact temperature and displacement measurements.

\subsection{Pitch system}

In most modern WTs, the pitch of the blades can be adjusted by hydraulic or electromagnetic actuators located in the base of each blade [39], in order to maximise power extraction from the wind, or to limit the WT load or rotational speed. WT pitch faults are very common and can be defined as a "deviation of the blade pitch angle from a predefined optimum for a given wind speed". In many cases, the electrical control only needs to be reset, which can be carried out remotely [227]. In more serious cases, the entire pitch control system of a blade can fail; it is reported in [39] that wear causes blade pitch bearings and associated control systems to fail prematurely, mainly because the large pitch control bearings are challenging to manufacture "with the appropriate tolerances and surface finishes seen in smaller bearings".

According to [55], only one commercial product (the Condition Diagnostics System) seems to include a pitch system CM option, but no details are given on the CM method used.

As the pitch system is operated within a control system, in many studies the methods proposed come from control theory and are model-based. Techniques for detection and isolation of faults in blade sensors and actuators are briefly reviewed in [228,229], with a view to fault-tolerant control. In [228], a benchmark challenge is proposed for various types of fault detection and isolation, and fault-tolerant control. An adaptive observer approach is proposed in [229] to detect and evaluate pitch actuator faults. Study [230] compares a Kalman-like observer approach with SVM learning for pitch fault detection. The method proposed in [231], to detect and quantify internal and external leakage in a hydraulic pitch actuator, relies on parameter estimation within a model of the hydraulic system.

Alternatively, a data-driven approach is proposed in [227] for the classification of blade pitch condition; based on the values of operational SCADA data, the RIPPER algorithm generates and optimises a set of logic rules aimed at helping the operator to make appropriate decisions concerning the planning of maintenance actions. The system is able to reduce, by up to $52 \%$, the number of alarms to be handled by the operator. A strong point of the proposed method is that it generates rules which are more often meaningful and intuitively understandable by a human operator, while still avoiding the complexity of physical failure modelling.

\subsection{Yaw system}

The yaw system is generally moved by several electric motors or hydraulic actuators. It is reported, in [232], that hydraulic yaw drives are less used in modern WTs because leakage issues led to higher maintenance needs. According to [39], yaw bearings "are extremely large and pose many manufacturing problems". Furthermore, "the yaw bearings and their control systems suffer from premature failure by wear".

It is suggested, in [121], that yaw errors can be detected by monitoring the frequency component of the electrical power corresponding to the main shaft rotational speed as a function of the total electrical power. Accurate yaw error estimation using LIDAR wind measurements is proposed in [233]. However, no studies specifically dedicated to fault detection within the yaw mechanism have been published.

According to [55], two commercially-available CM systems (Condition Diagnostics System, and CMSWind which is under development) seem to include yaw system CM features.

\subsection{Sensors}

Some WT measurements, such as generator and rotor speed measurements, or blade root torque, are used within WT control loops. It is then valuable to detect faults in the corresponding sensors with a view to fault-tolerant control. The sensor fault detection techniques proposed in the literature are generally model-based [234-237], which could be challenging for application to WECs whose modelling, as stated earlier in Sections 4.4 and 5.1.2, is significantly more complex than for WTs and TTs.

\section{Conclusion}

It can be seen from the present review that CBM techniques for MRE are extremely diverse and depend on the specific subsystem being monitored.

Regardless of the subsystem considered, the relatively remote location of OWTs, WECs and TTs makes data transmission to the shore difficult. Thus, it is preferable to select or develop CBM systems that are able to process and analyse data on-site with restricted computational power, and send only limited, condensed, information to the operator. This can be achieved by reducing the amount of raw data to process (i.e. by limiting the number of sensors, and by choosing techniques requiring low sampling rates) and by selecting computationally-efficient data-processing and classification tools.

Another important point to stress is that it is not often the case that one unique sensing technology, data processing tool, feature classification algorithm or prognosis technique can be judged to be better than every other one. Instead, a combination of different sensing technologies is often a cheaper and more reliable solution, and the preferable data processing tool, feature classification algorithm or prognostic technique depends on the case study considered and on the specific user's constraints. That is why the authors, throughout this work, have often preferred to highlight strong points and limitations of the methods mentioned, including applicability to TTs and WECs, and have provided references to more specialised reviews and comparative studies where necessary.

Concerning the nature and the number of sensors, there is clearly a trade-off between the accuracy of damage detection and the drawbacks of additional sensors in terms of cost, reliability and computational burden. On the contrary, operational data, such as electrical quantities, control data or WT SCADA data, are already available in normal operation, and thus are interesting to exploit in isolation or combined with purpose-specific sensors, thus simplifying diagnosis and prognosis at no extra cost.

System-level monitoring for WTs, based on SCADA data, has shown to be an efficient and cheap tool to incorporate into CBM systems, provided that relevant data are used in statistical and machine-learning tools, as well as some physical knowledge, when possible. The transposition of such methods to TTs should not be particularly challenging provided that comparable monitoring 
standards are adopted. Unlike WTs and TTs, which have a relatively simple dynamic response to the incoming air or water flow, WECs do not lend themselves easily to power curve monitoring. Finally, challenges specific to TTs and WECs, especially biofouling, require the development of techniques sensitive to the corresponding failure modes.

Subsystems that are closely related to control (generators, converters, pitch systems and hydraulics) lend themselves to model-based fault detection, more often with a view to fault-tolerant control. For these subsystems, a synergistic approach to control design and CBM techniques can be relevant. Furthermore, fault detection can be easily based on system variables that are already measured by the control system, thus avoiding the use of additional, possibly expensive sensors.

In contrast, for complex subsystems whose modelling is uneasy or demanding, such as structural components, it can be preferable to use data-driven or anomaly detection approaches, based on specific sensors. Strain measurement, VA and AE have shown to be suitable techniques for SHM, and many studies are now addressing the challenges related to their online implementation. AE and VA techniques seem to be particularly adaptable to TTs and WECs by making sensors waterproof and applying appropriate noise filtering techniques.

Concerning WT mechanical drive trains, health assessment through the widespread VA technique can be advantageously complemented by SCADA data as well as temperature, oil and electrical analysis, provided that additional sensors are cheap enough. Data-driven approaches for rotating machinery prognostics are still difficult to extend to TTs and WECs, due to data scarcity.

Generally speaking, WT load and speed variability has a strong impact on the suitability of sensing techniques, data processing tools and diagnosis and prognosis algorithms, whether it be for system-level PM, structural components, drive train and generator components, and even PE devices and power transformers. Similar issues are likely to influence CBM techniques for WECs and TTs although, in the latter case, the variability could be much less significant.

Some WEC-specific components, such as air and water turbines and LGs, would require specific work for CBM technique development. Even more importantly, there remains a vast area to explore in the field of hydraulic drivetrain CBM, while such systems are likely to be an essential part of many future WT, TT and WEC designs.

Finally, in addition to the diversity of designs and the lack of industrial incentive, a significant impediment to the development of CBM techniques for TTs and WECs within a short amount of time could be the scarcity and commercial sensitivity of historical data, especially failure data, which are necessary to design datadriven techniques and to validate new methods. Some studies dedicated to TTs have been influenced by this issue, such as [238], in which trends and relationships between many monitored parameters are identified and modelled in normal operating conditions as a basis for novelty detection techniques, and [239], which addresses the specific machine-learning issue of class-imbalance, which occurs when one of the classes is under-represented within the training data, in this case, the classes corresponding to damaged states.

\section{Acknowledgements}

This paper is based upon work supported by Science Foundation Ireland under Grant No. 12/RC/2302 for the Marine Renewable Ireland (MaREI) centre.

\section{References}

[1] McCrone A, Finance BNE. Global trends in renewable energy investment. Frankfurt: Frankfurt School of Finance and Management; 2012.

[2] Butler S. Prognostic algorithms for condition monitoring and remaining useful life estimation [Ph.D. thesis]. Maynooth, Ireland: NUI Maynooth; 2012.

[3] Sinha Y, Steel J. A progressive study into offshore wind farm maintenance optimisation using risk based failure analysis. Renew Sustain Energy Rev 2015;42:735-42. http://dx.doi.org/10.1016/j.rser.2014.10.087.

[4] Elasha F, Teixeira JA. Condition monitoring philosophy for tidal turbines. Int J Perform Eng 2014;10(5):521.

[5] O'Connor M, Lewis T, Dalton G. Weather window analysis of irish west coast wave data with relevance to operations and maintenance of marine renewables. Renew Energy 2013;52:57-66. http://dx.doi.org/10.1016/j. renene.2012.10.021

[6] Dinwoodie I, McMillan D, Revie M, Lazakis I, Dalgic Y. Development of a combined operational and strategic decision support model for offshore wind. Energy Procedia 2013;35:157-66. http://dx.doi.org/10.1016/j. egypro.2013.07.169.

[7] Dinwoodie I, Quail F, McMillan D. Analysis of offshore wind turbine operation and maintenance using a novel time domain meteo-ocean modeling approach. In: Proceedings of the ASME turbo expo 2012 on turbine technical conference and exposition. American Society of Mechanical Engineers; 2012. p. 847-57.

[8] Thons S, McMillan D. Condition monitoring benefit for offshore wind turbines. In: Proceedings of PMAPS; 2012.

[9] May A, McMillan D, Thöns S. Economic analysis of condition monitoring systems for offshore wind turbine sub-systems. In: Proceedings of EWEA; 2014.

[10] Ambuhl S, Marquis L, Kofoed JP, Dalsgaard Srensen J. Operationand maintenance strategies for wave energy converter. Proc Inst Mech Eng Part O: J Reliab. 〈http://dx.doi.org/10.1177/11748006X15577877〉. 〈http://pio.sagepub. com/content/early/2015/03/28/1748006X15577877.full.pdf + html〉.

[11] Blaabjerg F, Liu H, Loh PC. Marine energy generation systems and related monitoring and control. IEEE Instrum Meas Mag 2014;17(2):27-32. http://dx. doi.org/10.1109/MIM.2014.6810042.

[12] Magagna D, Uihlein A. 2014 jrc ocean energy status report [Technical report]. Joint Research Centre (JRC) of the European Commission; 2015. 〈http://dx. doi.org/10.2790/866387>.

[13] Mueller M, Wallace R. Enabling science and technology for marine renewable energy. Energy Policy 2008;36(12):4376-82. http://dx.doi.org/10.1016/j. enpol.2008.09.035.

[14] Tiron R, Mallon F, Dias F, Reynaud EG. The challenging life of wave energy devices at sea: a few points to consider. Renew Sustain Energy Rev 2015;43:1263-72. http://dx.doi.org/10.1016/j.rser.2014.11.105.

[15] Chen L, Lam W-H. A review of survivability and remedial actions of tidal current turbines. Renew Sustain Energy Rev 2015;43:891-900. http://dx.doi. org/10.1016/j.rser.2014.11.071.

[16] Vega L. Encyclopedia of Sustainability, Science and Technology. Ch. Ocean Thermal Energy Conversion. Springer; 2012. p. 7296-328.

[17] Schuster M, Fritz N, McEntee J, Graver T, Rumsey M, Hernandez-Sanchez B, Miller D, Johnson E. Externally bonded FBG strain sensors for structural health monitoring of marine hydrokinetic structures. In: Proceedings of the 2nd marine energy technology symposium (METS2014). Seattle, WA; 2014.

[18] Scheu M, Matha D, Hofmann M, Muskulus M. Maintenance strategies for large offshore wind farms. Energy Procedia 2012;24:281-8. http://dx.doi.org/ 10.1016/j.egypro.2012.06.110.

[19] Wind power. Renewable energy technologies: cost analysis series, IRENA working paper. Power Sector. Volume 1, Issue 5/5; June 2012.

[20] Yang W, Tavner PJ, Crabtree CJ, Feng Y, Oiu Y. Wind turbine condition monitoring: technical and commercial challenges. Wind Energy 2014;17 (5):673-93. http://dx.doi.org/10.1002/we.1508.

[21] Maples B, Saur G, Hand M, van de Pietermen R, Obdam T. Installation, operation, and maintenance strategies to reduce the cost of offshore wind energy (TP5000-57403). Denver: NREL; 2009.

[22] Shafiee M. Maintenance logistics organization for offshore wind energy: current progress and future perspectives. Renew Energy 2015;77:182-93. http://dx.doi.org/10.1016/i.renene.2014.11.045.

[23] Mrquez FPG, Tobias AM, Prez JMP, Papaelias M. Condition monitoring of wind turbines: techniques and methods. Renew Energy 2012:46:169-78.

[24] Tchakoua P, Wamkeue R, Ouhrouche M, Slaoui-Hasnaoui F, Tameghe TA Ekemb G. Wind turbine condition monitoring: state-of-the-artreview, new trends, and future challenges. Energies 2014;7:2595-630. http://dx.doi.org $10.3390 / e n 7042595$.

[25] Lu B, Li Y, Wu X, Yang Z. A review of recent advances in wind turbine condition monitoring and fault diagnosis. In: Proceedings of PEMWA - power electronics and machines in wind applications. IEEE; 2009. p. 1-7. 〈http://dx. doi.org/10.1109/PEMWA.2009.5208325).

[26] Feng Y, Qiu Y, Crabtree CJ, Long H, Tavner PJ. Monitoring wind turbine gearboxes. Wind Energy; 2009. 〈http://dx.doi.org/10.1002/we.1521〉.

[27] Daneshi-Far Z, Capolino G, Henao H. Review of failures and condition monitoring in wind turbine generators. In: Proceedings of the XIX international conference on electrical machines (ICEM); 2010. p. 1-6. 〈http://dx.doi. org/10.1109/ICELMACH.2010.5608150).

[28] Nie M, Wang L. Review of condition monitoring and fault diagnosis 
technologies for wind turbine gearbox. In: Proceedings of procedia \{CIRP\}, 2nd international through-life engineering services conference. 11; 2013. p. 87-90. 〈http://dx.doi.org/10.1016/j.procir.2013.07.018〉.

[29] Yang B, Zhang L, Zhang W, Ai Y. Non-destructive testing of wind turbine blades using an infrared thermography: a review. In: Proceedings of the 2013 international conference on materials for renewable energy and environment (ICMREE). Vol. 1; 2013. p. 407-10. 〈http://dx.doi.org/10.1109/ICMREE. 2013.6893694).

[30] Riera-Guasp M, Pons-Llinares J, Climente-Alarcon V, Vedreño-Santos F, Pineda-Sánchez M, Antonino-Daviu J, Puche-Panadero R, Perez-Cruz J, RogerFolch J. Diagnosis of induction machines under non-stationary conditions: concepts and tools. In: Proceedings of 2013 IEEE workshop on electrical machines design control and diagnosis (WEMDCD). IEEE; 2013. p. 220-31.

[31] Ciang CC, Lee JR, Bang HJ. Structural health monitoring for a wind turbine system: a review of damage detection methods. Meas Sci Technol. 19, 12.

[32] Li D, Ho SCM, Song G, Ren L, Li H. A review of damage detection methods for wind turbine blades. Smart Mater Struct. 24, 3.

[33] Zhou H, Dou H, Qin L, Chen Y, Ni Y, Ko J. A review of full-scale structural testing of wind turbine blades. Renew Sustain Energy Rev 2014;33:177-87.

[34] Hamilton A, Quail F. Detailed state of the art review for the different online/ inline oil analysis techniques in context of wind turbine gearboxes. J Tribol 2011;133(4):18. http://dx.doi.org/10.1115/1.4004903.

[35] Antoniadou I, Dervilis N, Papatheou E, Maguire AE, Worden K. Aspects of structural health and condition monitoring of offshore wind turbines. Philos Trans R Soc Lond. 〈http://dx.doi.org/10.1098/rsta.2014.0075〉.

[36] Rourke FO, Boyle F, Reynolds A. Tidal energy update 2009. Appl Energy 2010;87(2):398-409. http://dx.doi.org/10.1016/j.apenergy.2009.08.014.

[37] Zhang J, Moreau L, Machmoum M, Guillerm PE. State of the art in tidal current energy extracting technologies. In: Proceedings of the 2014 international conference on green energy; 2014. p. 1-7. 〈http://dx.doi.org/10.1109/ ICGE.2014.6835388>

[38] Zhou Z, Scuiller F, Charpentier J, Benbouzid M, Tang T. An up-to-date review of large marine tidal current turbine technologies. In: Proceedings of the 2014 international electronics and application conference and exposition (PEAC); 2014. p. 480-84. 〈http://dx.doi.org/10.1109/PEAC.2014.7037903〉.

[39] Wood RJK, Bahaj AS, Turnock SR, Wang L, Evans M. Tribological design constraints of marine renewable energy systems. Philos Trans R Soc Lond A: Math Phys Eng Sci 2010;368(1929):4807-27. http://dx.doi.org/10.1098/ rsta.2010.0192.

[40] Beaujean P, Khoshgoftaar T, Sloan J, Xiros N, Vendittis D. Monitoring ocean turbines: a reliability assessment. In: Proceedings of the 15th ISSAT international reliability and quality in design conference; 2009. p. 367-71.

[41] Zhou Z, Scuiller F, Charpentier J, Benbouzid M, Tang T. Power limitation control for a pmsg-based marine current turbine at high tidal speed and strong sea state. In: Proceedings of the 2013 IEEE international electric machines drives conference (IEMDC); 2013. p. 75-80. 〈http://dx.doi.org/10. 1109/IEMDC.2013.6556195>.

[42] Elasha F, Mba D, Teixeira JA. Failure prediction of tidal turbines gearboxes. In: Proceedings of the 3rd international workshop \& congress on emaintenance; 2014.

[43] Winter A. Differences in fundamental design drivers for wind and tidal turbines. In: Proceedings of the OCEANS. Spain: IEEE; 2011. p. 1-10. 〈http:// dx.doi.org/10.1109/Oceans-Spain.2011.6003647).

[44] Drew B, Plummer AR, Sahinkaya MN. A review of wave energy converter technology. Proc Inst Mech Eng Part A: J Power Energy 2009;223(8):887902. http://dx.doi.org/10.1243/09576509JPE782.

[45] Deane J, Dalton G, Gallachóir BÓ. Modelling the economic impacts of $500 \mathrm{MW}$ of wave power in ireland. Energy Policy 2012;45:614-27. http://dx. doi.org/10.1016/j.enpol.2012.03.012.

[46] Astariz S, Iglesias G. The economics of wave energy: a review. Renew Sustain Energy Rev 2015;45:397-408. http://dx.doi.org/10.1016/j.rser.2015.01.061.

[47] Prez-Collazo C, Greaves D, Iglesias G. A review of combined wave and offshore wind energy. Renew Sustain Energy Rev 2015;42(0):141-53. http://dx. doi.org/10.1016/j.rser.2014.09.032.

[48] Wilkinson M, Hendriks B, Spinato F, Gomez E, Bulacio H, Roca J, Tavner P, Feng Y, Long H. Methodology and results of the reliawind reliability field study. In: Proceedings of EWEC 2010. Warsaw; 2010.

[49] Blaabjerg F, Ma K. Future on power electronics for wind turbine systems. IEEE J Emerg Sel Top Power Electron 2013;1(3):139-52. http://dx.doi.org/ 10.1109/JESTPE.2013.2275978.

[50] Polinder H, Ferreira J, Jensen B, Abrahamsen A, Atallah K, McMahon R. Trends in wind turbine generator systems. IEEE J Emerg Sel Top Power Electron 2013;1(3):174-85. http://dx.doi.org/10.1109/JESTPE.2013.2280428.

[51] López I, Andreu J, Ceballos S, de Alegría IM, Kortabarria I. Review of wave energy technologies and the necessary power-equipment. Renew Sustain Energy Rev 2013;27:413-34. http://dx.doi.org/10.1016/j.rser.2013.07.009.

[52] Möller P, Todalshaug JH. Tank testing of high-efficiency phase-controlled wave energy convertor [Technical report]. MARINET (Marine Renewable Infrastructure Network, an EC-funded network of research centres and organisations); 2015.

[53] Stillinger C, Brekken T, von Jouanne A, Furthering the study of real-time life extending control for ocean energy conversion. In: Proceedings of the 2012 IEEE power and energy society general meeting; 2012, p. 1-9. 〈http://dx.doi. org/10.1109/PESGM.2012.6345460).

[54] Crabtree CJ. Condition monitoring techniques for wind turbines [Ph.D. thesis]. Durham, United Kingdom: Durham University; 2011.
[55] Crabtree C, Zappala D, Tavner P. Survey of commercially available condition monitoring systems for wind turbines [Technical report]. Durham University School of Engineering and Computing Sciences and the SUPERGEN Wind Energy Technologies Consortium; 2014.

[56] Feng Y, Qiu Y, Crabtree CJ, Long H, Tavner PJ. Use of scada and cms signals for failure detection and diagnosis of a wind turbine gearbox. In: Proceedings of the EWEA 2011. Brussels; 2011.

[57] Chen B, Zappalá D, Crabtree CJ, Tavner PJ. Survey of commercially available scada data analysis tools for wind turbine health monitoring [Technical report]. Durham University School of Engineering and Computing Sciences; 2014.

[58] Lindroth S, Leijon M. Offshore wave power measurements - a review. Renew Sustain Energy Rev 2011;15(9):4274-85.

[59] Lindblad L, Baudoin A, Leijon M. Measurement system for wave energy converter: design and implementation. In: Proceedings of the ASME 2014 33rd international conference on ocean, offshore and arctic engineering. American Society of Mechanical Engineers; 2014.

[60] Sultan I, Wells B, Wood S. Development of a wireless control and monitoring system for wave energy converters. In: Proceedings of oceans; 2012. p. 1-8. 〈http://dx.doi.org/10.1109/OCEANS.2012.6404951〉.

[61] Uluyol O, Parthasarathy G, Foslien W, Kim K. Power curve analytic for wind turbine performance monitoring and prognostics. In: Proceedings of annual conference of the prognostics and health management society. Vol. 20; 2011

[62] Sjolte J. Marine renewable energy conversion - grid and off-grid modeling, design and operation [Ph.D. thesis]; 2014.

[63] McNaughton J, Harper S, Sinclair R, Sellar B. Measuring and modelling the power curve of a commercial-scale tidal turbine. In: Proceedings of the 11th European wave and tidal energy conference. 6-11th September. Nantes, France; 2015.

[64] Lydia M, Kumar SS, Selvakumar AI, Kumar GEP. A comprehensive review on wind turbine power curve modeling techniques. Renew Sustain Energy Rev 2014;30:452-60. http://dx.doi.org/10.1016/j.rser.2013.10.030.

[65] Lapira E, Brisset D, Ardakani HD, Siegel D, Lee J. Wind turbine performance assessment using multi-regime modeling approach. Renew Energy 2012;45:86-95. http://dx.doi.org/10.1016/j.renene.2012.02.018.

[66] Yang W, Court R, Jiang J. Wind turbine condition monitoring by the approach of scada data analysis. Renew Energy 2013;53:365-76. http://dx.doi.org/ 10.1016/j.renene.2012.11.030.

[67] Skrimpas GA, Sweeney CW, Marhadi KS, Jensen BB, Mijatovic N, Holboll J. Detection of wind turbine power performance abnormalities using eigenvalue analysis. In: Proceedings of the 2014 annual conference of the prognostics and health management society; 2014.

[68] Butler S, Ringwood J, O'Connor F. Exploiting scada system data for wind turbine performance monitoring. In: Proceedings of the 2013 conference on control and fault-tolerant systems. SysTol. Nice, France; 2013.

[69] Kusiak A, Verma A. Monitoring wind farms with performance curves. IEEE Trans Sustain Energy 2013;4(1):192-9. http://dx.doi.org/10.1109/ TSTE.2012.2212470.

[70] Zhang Z, Kusiak A. Monitoring wind turbine vibration based on scada data. J Sol Energy Eng. 134, 2. 〈http://dx.doi.org/10.1115/1.4005753〉.

[71] Milan P, Waechter M, Peinke J. Stochastic modeling and performance monitoring of wind farm power production. J Renew Sustain Energy. 6, 3. 〈http:/| dx.doi.org/http://dx.doi.org/10.1063/1.4880235>.

[72] Wilkinson M, Darnell B, van Delft T, Harman K. Comparison of methods for wind turbine condition monitoring with scada data. IET Renew Power Gener 2014;8(4):390-7. http://dx.doi.org/10.1049/iet-rpg.2013.0318.

[73] Marvuglia A, Messineo A. Monitoring of wind farm power curves using machine learning techniques. Appl Energy 2012;98:574-83. http://dx.doi org/10.1016/j.apenergy.2012.04.037.

[74] Papatheou E, Dervilis N, Maguire E, Worden K. Wind turbine structural health monitoring: a short investigation based on scada data. In: Le Cam V, Mevel L, Schoefs F. editors. Proceedings of the EWSHM - 7th European workshop on structural health monitoring (IFFSTTAR). Nantes, France: Inria, Université de Nantes; 2014

[75] Schlechtingen M, Santos IF, Achiche S. Using data-mining approaches for wind turbine power curve monitoring: a comparative study. IEEE Trans Sustain Energy 2013;4(3):671-9.

[76] Schlechtingen M, Santos IF, Achiche S. Wind turbine condition monitoring based on scada data using normal behavior models. Part 1: system description. Appl Soft Comput 2013;13(1):259-70. http://dx.doi.org/10.1016/j. asoc.2012.08.033.

[77] Schlechtingen M, Santos IF. Wind turbine condition monitoring basedon scada data using normal behavior models. Part 2: application examples. App Soft Comput 2014;14(Part C):447-60. http://dx.doi.org/10.1016/j.asoc.2013. 09.016 .

[78] Farkas Z. Considering air density in wind power production. arXiv preprint; 2011. 〈arXiv:1103.2198〉.

[79] Talayero AP, Melero JJ, Beltran J, Lázaro R. Wind farm efficiency improvement using turbine's scada data. In: Proceedings of the European wind energy conference; 2011.

[80] Verma AP. Performance monitoring of wind turbines: a data-mining approach [Ph.D. thesis]. Iowa City, USA: University of Iowa; 2012.

[81] Farrar CR, Worden K. An introduction to structural health monitoring. Philos Trans R Soc Lond A: Math Phys Eng Sci 2007;365(1851):303-15. http://dx. doi.org/10.1098/rsta.2006.1928.

[82] Faulkner P, Cutter P, Owens A. Structural health monitoring systems in 
difficult environmentsoffshore wind turbines. In: Proceedings of the 6th European workshop on structural health monitoring; 2012.

[83] Davidson J, Mo C. Recent advances in energy harvesting technologies for structural health monitoring applications. Smart Mater Res. 〈http://dx.doi. org/doi:10.1155/2014/410316>.

[84] Joyce BS. Development of an electromagnetic energy harvester for monitoringwind turbine blades [Master's thesis]. Blacksburg, Virginia: Virginia Polytechnic Instituteand State University; 2011.

[85] Joyce BS, Farmer J, Inman DJ. Electromagnetic energy harvester for monitoring wind turbine blades. Wind Energy 2014;17(6):869-76. http://dx.doi org/10.1002/we.1602

[86] Benedetti M, Fontanari V, Zonta D. Structural health monitoring of wind towers: remote damage detection using strain sensors. Smart Mater Struct. 20,5 .

[87] Benedetti M, Fontanari V, Battisti L. Structural health monitoring of wind towers: residual fatigue life estimation. Smart Mater Struct. 22, 4.

[88] Soman RN, Malinowski PH, Ostachowicz WM. Bi-axial neutral axis tracking for damage detection in wind-turbine towers. Wind Energy. 〈http://dx.doi. org/10.1002/we.1856>.

[89] López-Higuera JM, Rodriguez Cobo L, Quintela Incera A, Cobo A. Fiber optic sensors in structural health monitoring. J Light Technol 2011;29(4):587-608.

[90] Grosvenor RI, Prickett PW, Frost C, M. Allmark J. Performance and condition monitoring of tidal stream turbines.

[91] Togneri M, Masters I, Allmark M, Elasha F. Unsteady bemt for fault diagnosis and prognosis in tidal stream turbines. In: Proceedings of the 11th European wave and tidal energy conference. 6-11th September 2015. Nantes, France; 2015.

[92] Finnegan W, Goggins J. Numerical modeling to aid in the structural health monitoring of wave energy converters. Key Eng Mater 2013;569:595-602.

[93] Devriendt C, Magalhães F, Weijtjens W, De Sitter G, Cunha Á, Guillaume P. Structural health monitoring of offshore wind turbines using automated operational modal analysis. Struct Health Monit 2014;13(6):644-59.

[94] Dervilis N, Choi M, Taylor S, Barthorpe R, Park G, Farrar C, et al. On damage diagnosis for a wind turbine blade using pattern recognition. J Sound Vib 2014;333(6):1833-50. http://dx.doi.org/10.1016/j.jsv.2013.11.015.

[95] Myrent N, Adams DE, Griffith DT. Wind turbine blade shear web disbond detection using rotor blade operational sensing and data analysis. Philos Trans R Soc Lond A: Math Phys Eng Sci. 373, 2035. 〈http://dx.doi.org/10.1098/ rsta.2014.0345>.

[96] Di Lorenzo E, Manzato S, Peeters B, Marulo F, Structural health monitoring techniques applied to operating wind turbines. In: Cunha PRGMA, Caetano E, editors. Proceedings of the 9th international conference on structural dynamics (EURODYN 2014). Porto, Portugal; 2014. p. 2255-61.

[97] Iliopoulos A, Devriendt C, Guillaume P, Van Hemelrijck D. Continuous fatigue assessment of an offshore wind turbine using a limited number of vibration sensors. In: Le Cam V, Mevel L, Schoefs F, editors. Proceedings of the EWSHM - 7th European workshop on structural health monitoring (IFFSTTAR). Nantes, France: Inria, Université de Nantes; 2014

[98] Tippmann J, Zhu X, di Scalea FL. Application of damage detection methods using passive reconstruction of impulse response functions. Philos Trans $\mathrm{R}$ Soc Lond A: Math Phys Eng Sci. 373, 2035.

[99] Weijtjens W, Verbelen T, De Sitter G, Devriendt C, Data normalization for foundation shm of an offshore wind turbine: a real-life case study. In: Proceedings of the EWSHM-7th European workshop on structural health monitoring; 2014

[100] Shi W, Park H-C, Baek J-H, Kim C-W, Kim Y-C, Shin H-K. Study on the marine growth effect on the dynamic response of offshore wind turbines. Int J Precis Eng Manuf 2012;13(7):1167-76. http://dx.doi.org/10.1007/s12541-012-0155-7.

[101] Mahfuz H, Akram M. Life prediction of composite turbine blades under random ocean current and velocity shear. In: Proceedings of OCEANS. Spain: IEEE; 2011. p. 1-7. http://dx.doi.org/10.1109/Oceans-Spain.2011.6003526.

[102] Zhou F, Mahfuz H, Alsenas GM, Hanson HP. Static and fatigue analysis of composite turbine blades under random ocean current loading. Mar Technol Soc J 2013;47(2):59-69. http://dx.doi.org/10.4031/MTSJ.47.2.6.

[103] Li H, Hu Z, Chandrashekhara K, Du X, Mishra R. Reliability-based fatigue life investigation for a medium-scale composite hydrokinetic turbine blade. Ocean Eng 2014;89:230-42. http://dx.doi.org/10.1016/j.oceaneng.2014.08.006.

[104] Tandon N, Choudhury A A review of vibration and acoustic measurement methods for the detection of defects in rolling element bearings. Tribol Int 1999;32(8):469-80. http://dx.doi.org/10.1016/S0301-679X(99)00077-8.

[105] Tsopelas NK, Papasalouros DG, Anastasopoulos AA, Kourousis DA, Dong JW. Acoustic emission for structural integrity assessment of wind turbine blades. In: G. Shen et al. (editors), Advances in acoustic emission technology. Springer; 2015, p. 369-82.

[106] Walsh J, Bashir I, Thies PR, Blondel P, Johanning L. Acoustic emission health monitoring of marine renewables - illustration with a wave energy converter in Falmouth Bay (UK). In: Proceedings of OCEANS'15 MTS/IEEE Genova conference. Genova, Italy; May 2015. p. 18-21.

[107] Baqersad J, Niezrecki C, Avitabile P. Full-field dynamic strain prediction on a wind turbine using displacements of optical targets measured by stereophotogrammetry. Mech Syst Signal Process 2015(62-63):284-95. http://dx. doi.org/10.1016/j.ymssp.2015.03.021.

[108] Winstroth J, Schoen L, Ernst B, Seume JR. Wind turbine rotor blade monitoring using digital image correlation: a comparison to aeroelastic simulations of a multi-megawatt wind turbine. J Phys: Conf Ser. 524, 1.

[109] Carr J, Baqersad J, C. Niezrecki, Avitabile P. Full-field dynamic strain on wind turbine blade using digital image correlation techniques and limited sets of measured data from photogrammetric targets. Exp Tech. 〈http://dx.doi.org/ 10.1111/ext.12129).

[110] Ozbek M, Rixen DJ. Structural health monitoring of multi-mw-scale wind turbines by non-contact optical measurement techniques: an application on a 2.5-MW wind turbine. In: Energy systems and management, springer proceedings in energy. Springer International Publishing; 2015, p. 125-36. 〈http://dx.doi.org/10.1007/978-3-319-16024-5).

[111] Chatzakos P, Avdelidis N, Hrissagis K, Gan TH. Autonomous infrared (ir) thermography based inspection of glass reinforced plastic (grp) wind turbine blades (wtbs). In: Proceedings of the 2010 IEEE conference on robotics automation and mechatronics (RAM); 2010, p. 557-62. 〈http://dx.doi.org/10. 1109/RAMECH.2010.5513132>.

[112] Ye G, Neal B, Boot A, Kappatos V, Selcuk C, Gan TH. Development of an ultrasonic ndt system for automated in-situ inspection of wind turbine blades. In: Le Cam V, Mevel L, Schoefs F, editors. Proceedings of the EWSHM - 7th European workshop on structural health monitoring (IFFSTTAR). Nantes, France: Inria, Université de Nantes; 2014.

[113] Moradi M, Sivoththaman S. MEMS multisensor intelligent damage detection for wind turbines. IEEE Sens J 2015;15(3):1437-44. http://dx.doi.org/10.1109/ JSEN.2014.2362411.

[114] Niezrecki C, Avitabile P, Chen J, Sherwood J, Lundstrom T, LeBlanc B, Hughes S, Desmond M, Beattie A, Rumsey M, et al. Inspection and monitoring of wind turbine blade-embedded wave defects during fatigue testing. Struct Health Monit. 〈http://dx.doi.org/10.1177/1475921714532995〉.

[115] Griffith DT, Yoder NC, Resor B, White J, Paquette J. Structural health and prognostics management for the enhancement of offshore wind turbine operations and maintenance strategies. Wind Energy 2014;17(11):1737-51. http://dx.doi.org/10.1002/we.1665.

[116] Website of the european remo project. URL 〈http://www.remo-project.eu/〉.

[117] Brown AC, Paasch R. Fatigue life distribution for a simple wave energy converter. In: Proceedings of the 2nd marine energy technology symposium (METS2014). Seattle, WA; 2014.

[118] Coe RG, Neary VS. Review of methods for modeling wave energy converte survival in extreme sea states. In: Proceedings of the 2nd marine energy technology symposium (METS2014). Seattle, WA; 2014.

[119] Wilkinson M, Spinato F, Tavner P. Condition monitoring of generators and other subassemblies in wind turbine drive trains. In: Proceedings of the SDEMPED 2007 - IEEE international symposium on diagnostics for electric machines, power electronics and drives; 2007. p. 388-92. 〈http://dx.doi.org/ 10.1109/DEMPED.2007.4393125>.

[120] MusialW, Butterfield S, McNiff B. Improving wind turbine gearbox reliability. In: Proceedings of NREL - to be presented at the 2007 European wind energy conference. Milan, Italy; May 2007.

[121] Hameed Z, Hong Y, Cho Y, Ahn S, Song C. Condition monitoring and fault detection of wind turbines and related algorithms: a review. Renew Sustain Energy Rev 2009;13(1):1-39. http://dx.doi.org/10.1016/j.rser.2007.05.008.

[122] Caselitz P, Giebhardt G. Advanced maintenance and repair for offshore wind farms using fault prediction techniques. Institut fuer Solare Energieversorgungstechnik (ISET), Div. Energy Conversion and Control Engineering, Konigstor 59, D-34119 Kassel, Germany; 2002.

[123] Isko V, Mykhaylyshyn V, Moroz I, Ivanchenko O, Rasmussen P. Remote wind turbine generator condition monitoring with mita-teknik's wp4086 system. In: Proceedings of the 2010 European wind energy conference (EWEC) \& exhibition. Warsaw, Poland; 2010 April. p. 20-23.

[124] Wang WQ Ismail F, Golnaraghi MF. Assessment of gear damage monitoring techniques using vibration measurements. Mech Syst Signal Process 2001;15 (5):905-22. http://dx.doi.org/10.1006/mssp.2001.1392.

[125] Brie D, Tomczak M, Oehlmann H, Richard A. Gear crack detection by adaptive amplitude and phase demodulation. Mech Syst Signal Process 1997;11 (1):149-67. http://dx.doi.org/10.1006/mssp.1996.0068.

[126] Natarajan S. Gear box fault diagnosis using hilbert transform and study on classification of features by support vector machine. Int J Hybrid Inf Technol 2014;7(4):69-82.

[127] Randall RB. A history of cepstrum analysis and its application to mechanical problems. In: Proceedings of international conference. p. 29-30.

[128] Barszcz T, Randall RB. Application of spectral kurtosis for detection of a tooth crack in the planetary gear of a wind turbine. Mech Syst Signal Process 2009;23(4):1352-65. http://dx.doi.org/10.1016/j.ymssp.2008.07.019.

[129] Avendano-Valencia L, Fassois S. Stationary and non-stationary random vibration modelling and analysis for an operating wind turbine. Mech Syst Signal Process 2014;47:263-85. http://dx.doi.org/10.1016/i.ymssp.2013.07.022.

[130] Antoni J, Randall R. The spectral kurtosis: application to the vibratory surveillance and diagnostics of rotating machines. Mech Syst Signal Process 2006;20(2):308-31. http://dx.doi.org/10.1016/i.ymssp.2004.09.002.

[131] Yao X, Guo C, Zhong M, Li Y, Shan G, Zhang Y. Wind turbine gearbox fault diagnosis using adaptive morlet wavelet spectrum. In: Proceedings of the ICICTA '09 second international conference on intelligent computation technology and automation. Vol. 2; 2009. p. 580-83. 〈http://dx.doi.org/10. 1109/ICICTA.2009.375>.

[132] Yan R, Gao RX, Chen X. Wavelets for fault diagnosis of rotary machines: a review with applications. Signal Process 2014;96:1-15. http://dx.doi.org/ 10.1016/j.sigpro.2013.04.015.

[133] Ziaja A, Antoniadou I, Barszcz T, Staszewski WJ, Worden K. Fault detection in rolling element bearings using wavelet-based variance analysis and novelty detection. J Vib Control 2014:1-16. http://dx.doi.org/10.1177/1077546314532859. 
[134] Huang NE, Shen Z, Long SR, Wu MC, Shih HH, Zheng Q et al. The empirical mode decompositionand the hilbert spectrum for nonlinear and non-stationary time series analysis. Proc R Soc Lond A: Math Phys Eng Sci 1988;454 (1971). http://dx.doi.org/10.1098/rspa.1998.0193.

[135] Lei Y, Lin J, He Z, Zuo MJ. A review on empirical mode decomposition in fault diagnosis of rotating machinery. Mech Syst Signal Process 2013;35(1-2):10826. http://dx.doi.org/10.1016/j.ymssp.2012.09.015.

[136] Antoniadou I. Accounting for nonstationarity in the condition monitoringof wind turbine gearboxes [Ph.D. thesis]. Sheffield, United Kingdom: The University of Sheffield; 2013.

[137] Teng W, Wang F, Zhang K, Liu Y, Ding X. Pitting fault detection of a wind turbine gearbox using empirical mode decomposition. Stroj Vestnik - J Mech Eng 2014;60(1):12-20.

[138] Antoniadou I, Manson G, Staszewski W, Barszcz T, Worden K. A time-frequency analysis approach for condition monitoring of a wind turbine gearbox under varying load conditions. Mech Syst Signal Process 2015(64-65):188216. http://dx.doi.org/10.1016/j.ymssp.2015.03.003.

[139] Daubechies I, Lu J, Wu H-T. Synchrosqueezed wavelet transforms: an empirical mode decomposition-like tool. Appl Comput Harmon Anal 2011;30 (2):243-61. http://dx.doi.org/10.1016/j.acha.2010.08.002

[140] Wu H-T, Flandrin P, Daubechies I. One or two frequencies? The synchrosqueezing answers Adv Adapt Data Anal 2011;3(1-2):29-39.

[141] Feng Z, Chen X, Liang M. Iterative generalized synchrosqueezing transform for fault diagnosis of wind turbine planetary gearbox under nonstationary conditions. Mech Syst Signal Process 2015;52-53:360-75. http://dx.doi.org/ 10.1016/j.ymssp.2014.07.009.

[142] Bouchikhi E, Choqueuse V, Benbouzid M, Charpentier J, Barakat G. A comparative study of time-frequency representations for fault detection in wind turbine. In: Proceedings of the IECON 2011 - 37th annual conference on IEEE industrial electronics society; 2011. p. 3584-89. 〈http://dx.doi.org/10.1109/IE CON.2011.6119891>

[143] Murray C, Asher M, Lieven N, Mulroy M, Ng C, Morrish P. Wind turbine drivetrain health assessment using discrete wavelet transforms and an artificial neural network. In: Proceedings of renewable power generation conference (RPG 2014). 3rd.

[144] Jedliński L, Jonak J. Early fault detection in gearboxes based on support vector machines and multilayer perceptron with a continuous wavelet transform. Appl Soft Comput 2015;30:636-41. http://dx.doi.org/10.1016/j.asoc.2015. 02.015.

[145] Samanta B. Gear fault detection using artificial neural networks and support vector machines with genetic algorithms. Mech Syst Signal Process 2004;18 (3):625-44. http://dx.doi.org/10.1016/S0888-3270(03)00020-7.

[146] Li PF, Xiang JW. Fault diagnosis of gearbox in wind turbine based on wavelet transform and support vector machine. In: Applied mechanics and materials. Trans Tech Publication. Vol. 536; 2014. p. 18-21.

[147] Tang B, Song T, Li F, Deng L. Fault diagnosis for a wind turbine transmission system based on manifold learning and shannon wavelet support vector machine. Renew Energy 2014;62:1-9. http://dx.doi.org/10.1016/j.renene. 2013.06.025.

[148] Santos P, Villa LF, Reñones A, Bustillo A, Maudes J. An SVM-based solution for fault detection in wind turbines. Sensors 2015;15(3):5627-48. http://dx.doi. org/10.3390/s150305627.

[149] Kan MS, Tan AC, Mathew J. A review on prognostic techniques for non-stationary and non-linear rotating systems. Mech Syst Signal Process. 〈http://dx. doi.org/http://dx.doi.org/10.1016/j.ymssp.2015.02.016).

[150] Zappala D, Tavner P, Crabtree C, Sheng S. Side-band algorithm for automatic wind turbine gearbox fault detection and diagnosis. IET Renew Power Gener 2014;8(4):380-9. http://dx.doi.org/10.1049/iet-rpg.2013.0177.

[151] Wald RD. Vibration analysis for ocean turbine reliability models [Ph.D. thesis]. Boca Raton, Florida, USA: Florida Atlantic University; 2012.

[152] Duhaney J, Khoshgoftaar TM, Cardei I, Alhalabi B, Sloan JC. Applications of data fusion in monitoring inaccessible ocean machinery. In: Proceedings of the 16th international ISSAT on reliability and quality in design. 5; 2010, 7.

[153] Duhaney J, Khoshgoftaar T, Wald R. Applying feature selection to short time wavelet transformed vibration data for reliability analysis of an ocean turbine. In: Proceedings of the 2012 11th international conference on machine learning and applications (ICMLA). Vol. 1; 2012. p. 330-37. 〈http://dx.doi.org/ 10.1109/ICMLA.2012.62).

[154] Duhaney J, Khoshgoftaar TM, Sloan JC. Feature level sensor fusion for improved fault detection in mcm systems for ocean turbines. In: Proceedings of the twenty-fourth international FLAIRS conference; 2011.

[155] Duhaney J, Khoshgoftaar T. Decision level fusion of wavelet features for ocean turbine state detection. In: Proceedings of the 201211 th international conference on machine learning and applications (ICMLA). Vol. 2; 2012. p. 53137. 〈http://dx.doi.org/10.1109/ICMLA.2012.179〉.

[156] Coronado D, Kupferschmidt C, Assessment and validation of oil sensor systems for on-line oil condition monitoring of wind turbine gearboxes. In: Proceedings of procedia technology, 2nd International conference on systemintegrated intelligence: challenges for product and production engineering. 15; 2014. p. 748-55. 〈http://dx.doi.org/http://dx.doi.org/10.1016/j.protcy. 2014.09.047خ.

[157] Salgueiro J, Peršin G, Vižintin J, Ivanovič M, Dolenc B. On-line oil monitoring and diagnosis. Stroj Vestnik - J Mech Eng 2013;59(10):604-12. http://dx.doi. org/10.5545/sv-jme.2013.973.

[158] Yoon J, He D. Development of an efficient prognostic estimator. J Fail Anal Prev 2015;15(1):129-38. http://dx.doi.org/10.1007/s11668-014-9902-7.
[159] Eren L, Devaney M. Bearing damage detection via wavelet packet decomposition of the stator current. IEEE Trans Instrum Meas 2004;53(2):431-6. http://dx.doi.org/10.1109/TIM.2004.823323.

[160] Kar C, Mohanty A. Monitoring gear vibrations through motor current signature analysis and wavelet transform. Mech Syst Signal Process 2006;20 (1):158-87. http://dx.doi.org/10.1016/j.ymssp.2004.07.006.

[161] Kar C, Mohanty A. Multistage gearbox condition monitoring using motor current signature analysis and kolmogorov-smirnov test. J Sound Vib 2006;290(1-2):337-68. http://dx.doi.org/10.1016/j.jsv.2005.04.020.

[162] Kia S, Henao H, Capolino G-A. Gearbox monitoring using induction machine stator current analysis. In: Proceedings of the SDEMPED 2007 - IEEE international symposium on diagnostics for electric machines, power electronics and drives; 2007. p. 149-54. 〈http://dx.doi.org/10.1109/DEMPED.2007. 4393086>

[163] Cibulka J, Ebbesen MK, Robbersmyr KG. Bearing fault detection in induction motor-gearbox drivetrain. J Phys: Conf Ser. 364, 1

[164] Yang W, Tavner P, Wilkinson M. Condition monitoring and fault diagnosis of a wind turbine synchronous generator drive train. IET Renew Power Gener. 〈http://dx.doi.org/10.1049/iet-rpg:20080006〉.

[165] Neti P, Zhang P, Shah M, Younsi K. Electrical signature analysis based online monitoring of drive-trains for doubly-fed wind generators. In: Proceedings of the IECON 2012 - 38th annual conference on IEEE industrial electronics society; 2012. p. 1764-69. 〈http://dx.doi.org/10.1109/IECON.2012.6388934〉.

[166] Lu D, Gong X, Qiao W. Current-based diagnosis for gear tooth breaks in wind turbine gearboxes. In: Proceedings of the 2012 IEEE energy conversion congress and exposition (ECCE); 2012. p. 3780-3786. 〈http://dx.doi.org/10. 1109/ECCE.2012.6342293).

[167] Madsen BN. Condition monitoring of wind turbines by electric signature analysis [Master's thesis]. Copenhagen, Denmark: Technical University of Denemark: 2011.

[168] Zhen L, Zhengjia H, Yanyang Z, Xuefeng C. Bearing condition monitoring based on shock pulse method and improved redundant lifting scheme. Math Comput Simul 2008;79(3):318-38. http://dx.doi.org/10.1016/j.matcom.2007. 12.004

[169] Soua S, Lieshout PV, Perera A, Gan T-H, Bridge B. Determination of the combined vibrational and acoustic emission signature of a wind turbine gearbox and generator shaft in service as a pre-requisite for effective condition monitoring. Renew Energy 2013;51(0):175-81. http://dx.doi.org/ 10.1016/j.renene.2012.07.004.

[170] Butler S, O'Connor F, Farren D, Ringwood J. A feasibility study into prognostics for the main bearing of a wind turbine. In: Proceedings of the 2012 IEEE international conference on control applications (CCA). Dubrovnik, Croatia; 2012.

[171] Bangalore P, Tjernberg L. An artificial neural network approach for early fault detection of gearbox bearings. IEEE Trans Smart Grid 2015;6(2):980-7. http: //dx.doi.org/10.1109/TSG.2014.2386305.

[172] Al-Tubi I, Long H, Tavner P, Shaw B, Zhang J. Probabilistic analysis of gear flank micro-pitting risk in wind turbine gearbox using scada data. IET Renew Power Gener.

[173] Gong X. Online nonintrusive condition monitoring and fault detection for wind turbines [Ph.D. thesis]. Lincoln, NE, USA: Department of Electrical Engineering, University of Nebraska; 2012.

[174] Heng A, Zhang S, Tan AC, Mathew J. Rotating machinery prognostics: state of the art, challenges and opportunities. Mech Syst Signal Process 2009;23 (3):724-39. http://dx.doi.org/10.1016/j.ymssp.2008.06.009.

[175] Lee J, Wu F, Zhao W, Ghaffari M, Liao L, Siegel D. Prognostics and health management design for rotary machinery systems - reviews, methodology and applications. Mech Syst Signal Process 2014;42(1-2):314-34. http://dx. doi.org/10.1016/j.ymssp.2013.06.004.

[176] Elasha F, Mba D, Teixeira JA. Gearboxes prognostics with application to tidal turbines. In: Proceedings of twelfth international conference on condition monitoring and machinery failure prevention technologies. Oxford, UK; 2015

[177] Salter S, Rea M. Hydraulics for wind. In: Proceedings of European wind energy conference. Hamburg, Germany; October 1984. p. 22-26.

[178] Innes-Wimsatt E, Qin C, Loth E. Economic benefits of hydraulic-electric hybrid wind turbines. Int. J. Environ. Stud. 2014;71(6):812-27. http://dx.doi.org 10.1080/00207233.2014.967101.

[179] Carroll J, McDonald A, McMillan D, Feuchtwang J. Offshore availability for wind turbines with a hydraulic drive train. In: Proceedings of the 3rd renewable power generation conference (RPG 2014); 2014. p. 1-6. 〈http://dx. doi.org/10.1049/cp.2014.0886>.

[180] Garimella P, Yao B. Model based fault detection of an electro-hydraulic cylinder. In: Proceedings of the 2005 American control conference. vol. 1; 2005. p. 484-489. 〈http://dx.doi.org/10.1109/ACC.2005.1469982〉.

[181] Nurmi J, Mattila J. Detection and isolation of leakage and valve faults in hydraulic systems in varying loading conditions, Part 2: fault detection and isolation scheme. Int J Fluid Power 2012;13(1):17-27. http://dx.doi.org/ 10.1080/14399776.2012.10781043.

[182] Rezazadeh AS, Koofigar HR, Hosseinnia S. Robust leakage detection for electro hydraulic actuators using an adaptive nonlinear observer. Int J Precis Eng Manuf 2014;15(3):391-7.

[183] Goharrizi A, Sepehri N. Internal leakage detection in hydraulic actuators using empirical mode decomposition and hilbert spectrum. IEEE Trans Instrum Meas 2012;61(2):368-78. http://dx.doi.org/10.1109/TIM.2011.2161938.

[184] May M, Sepehri N, Kinsner W. Hydraulic actuator internal leakage detection using cross-correlation time series analysis. In: Proceedings of the ASME/ 
BATH 2014 symposium on fluid power and motion control. American Society of Mechanical Engineers; 2014.

[185] Heath TV. A review of oscillating water columns. Philos Trans R Soc Lond A: Math Phys Eng Sci 2011;370(1959):235-45. http://dx.doi.org/10.1098/ rsta.2011.0164.

[186] Oberholster A, Heyns P. Online condition monitoring of axial-flow turbomachinery blades using rotor-axial Eulerian laser doppler vibrometry. Mech Syst Signal Process 2009;23(5):1634-43. http://dx.doi.org/10.1016/j. ymssp.2009.01.001.

[187] Zhan L, Peng Y, Chen X. Cavitation vibration monitoring in the kaplan turbine. In: Proceedings of the APPEEC 2009 Asia-pacific power and energy engineering conference; 2009. p. 1-4. 〈http://dx.doi.org/10.1109/APPEEC. 2009.4918211>.

[188] Escaler X, Egusquiza E, Farhat M, Avellan F, Coussirat M. Detection of cavitation in hydraulic turbines. Mech Syst Signal Process 2006;20(4):983-1007.

[189] Riera-Guasp M, Antonino-Daviu J, Capolino G-A. Advances in electrical machine, power electronic, and drive condition monitoring and fault detection: state of the art. IEEE Trans Ind Electron 2015;62(3):1746-59. http://dx.doi. org/10.1109/TIE.2014.2375853.

[190] Tavner P. Review of condition monitoring of rotating electrical machines. Electr Power Appl IET 2008;2(4):215-47. http://dx.doi.org/10.1049/ iet-epa:20070280.

[191] Henao H, Capolino G-A, Fernandez-Cabanas M, Filippetti F, Bruzzese C Strangas E, et al. Trends in fault diagnosis for electrical machines: a review of diagnostic techniques. IEEE Ind Electron Mag 2014;8(2):31-42. http://dx.doi. org/10.1109/MIE.2013.2287651.

[192] Vedreño-Santos F, Riera-Guasp M, Henao H, Pineda-Sánchez M, Puche-Panadero R. Diagnosis of rotor and stator asymmetries in wound-rotor induction machines under nonstationary operation through the instantaneous frequency. IEEE Trans Ind Electron 2014;61(9):4947-59. http://dx.doi.org 10.1109/TIE.2013.2288192.

[193] Watson SJ, Xiang BJ, Yang W, Tavner PJ, Crabtree CJ. Condition monitoring of the power output of wind turbine generators using wavelets. IEEE Trans Energy Convers. 25, 3.

[194] Yang W, Tavner P, Crabtree C, Wilkinson M. Cost-effective condition monitoring for wind turbines. IEEE Trans Ind Electron 2010;57(1):263-71. http: //dx.doi.org/10.1109/TIE.2009.2032202.

[195] Gritli Y, Zarri L, Rossi C, Filippetti F, Capolino G, Casadei D. Advanced diagnosis of electrical faults in wound-rotor induction machines. IEEE Trans Ind Electron 2013;60(9):4012-24. http://dx.doi.org/10.1109/TIE.2012.2236992.

[196] Pons-Llinares J, Riera-Guasp M, Antonino-Daviu J, Vedreño-Santos F. Transient diagnosis of induction generators via atom-based time-frequency transforms. In: Proceedings of the 2014 international conference on electrical machines (ICEM); 2014. p. 1793-99. 〈http://dx.doi.org/10.1109/ICELMACH. 2014.6960426).

[197] Yang W, Tavner P, Court R. An online technique for condition monitoring the induction generators used in wind and marine turbines. Mech Syst Signal Process 2013;38(1):103-12. http://dx.doi.org/10.1016/j.ymssp.2012.03.002 (condition monitoring of machines in non-stationary operations).

[198] Zaggout M, Tavner P, Crabtree C, Ran L. Detection of rotor electrical asymmetry in wind turbine doubly-fed induction generators. IET Renewable Power Generation.

[199] Abadi M, Cruz S, Gonçalves A, Gonçalves P, Mendes A, Ribeiro A, Silva F. Detection of stator and rotor faults in a dfig based on the stator reactive power analysis. In: Proceedings of the IECON 2014 - 40th annual conference of the ieee industrial electronics society; 2014. p. 2037-43. 〈http://dx.doi.org/ 10.1109/IECON.2014.7048782>.

[200] Benelghali S, Benbouzid M, Charpentier J. Generator systems for marine current turbine applications: a comparative study. IEEE J Ocean Eng 2012;37 (3):554-63. http://dx.doi.org/10.1109/JOE.2012.2196346.

[201] Jlassi I, Estima J, El Khil S, Bellaaj N, Marques Cardoso A. Multiple open-circuit faults diagnosis in back-to-back converters of pmsg drives for wind turbine systems. IEEE Trans Power Electron 2015;30(5):2689-702. http://dx.doi.org 10.1109/TPEL.2014.2342506.

[202] Blaabjerg F, Chen Z, Teodorescu R, Iov F. Power electronics in wind turbine systems. In: Proceedings of the 2006 CES/IEEE 5th international power electronics and motion control conference (IPEMC 2006). Vol. 1; 2006. p. 1 11. 〈http://dx.doi.org/10.1109/IPEMC.2006.4777946〉.

[203] Ran L, Konaklieva S, McKeever P, Mawby P. Condition monitoring of power electronics for offshore wind. Eng Technol Ref. 1, 1.

[204] Wang H, Liserre M, Blaabjerg F. Toward reliable power electronics: challenges, design tools, and opportunities. IEEE Ind Electron Mag 2013;7(2):1726. http://dx.doi.org/10.1109/MIE.2013.2252958.

[205] MacEnri J, Reed M, Thiringer T. Power quality performance of the tidal energy converter, seagen. In: Proceedings of the ASME 2011 30th international conference on ocean, offshore and arctic engineering. American Society of Mechanical Engineers; 2011. p. 529-36.

[206] Molinas M, Skjervheim O, Andreasen P, Undeland T, Hals J, Moan T, Sorby B Power electronics as grid interface for actively controlled wave energy converters. In: Proceedings of the ICCEP '07 international conference on clean electrical power; 2007, p. 188-95. 〈http://dx.doi.org/10.1109/ICCEP.2007. 384210>.

[207] Lu B, Sharma S. A literature review of igbt fault diagnostic and protection methods for power inverters. IEEE Trans Ind Appl 2009;45(5):1770-7. http: //dx.doi.org/10.1109/TIA.2009.2027535.

[208] Freire N, Estima J, Marques Cardoso A. Open-circuit fault diagnosis in pmsg drives for wind turbine applications. IEEE Trans Ind Electron 2013;60 (9):3957-67. http://dx.doi.org/10.1109/TIE.2012.2207655.

[209] Estima J, Freire N, Cardoso A. Recent advances in fault diagnosis by park's vector approach. In: Proceedings of the 2013 IEEE workshop on electrical machines design control and diagnosis (WEMDCD); 2013. p. 279-88. 〈http:// dx.doi.org/10.1109/WEMDCD.2013.6525187〉.

[210] Wang H, Liserre M, Blaabjerg F, de Place Rimmen P, Jacobsen J, Kvisgaard T, et al. Transitioning to physics-of-failure as a reliability driver in power electronics. IEEE J Emerg Sel Top Power Electron 2014;2(1):97-114. http://dx. doi.org/10.1109/JESTPE.2013.2290282.

[211] Yang S, Xiang D, Bryant A, Mawby P, Ran L, Tavner P. Condition monitoring for device reliability in power electronic converters: a review. IEEE Trans Power Electron 2010;25(11):2734-52. http://dx.doi.org/10.1109/TPEL.2010. 2049377.

[212] Oh H, Han B, McCluskey P, Han C, Youn B. Physics-of-failure, condition monitoring, and prognostics of insulated gate bipolar transistor modules: a review. IEEE Trans Power Electron 2015;30(5):2413-26. http://dx.doi.org/ 10.1109/TPEL.2014.2346485.

[213] Yi X, Ng C, McKeever P, Little C, Hillmansen S. Life estimation modelling for power electronics used in wind turbines. In: Proceedings of the 7th IET international conference on power electronics, machines and drives (PEMD 2014); 2014. p. 1-5. 〈http://dx.doi.org/10.1049/cp.2014.0407〉.

[214] Givaki K, Parker M, Jamieson P. Estimation of the power electronic converter lifetime in fully rated converter wind turbine for onshore and offshore wind farms. In: Proceedings of the 7th IET international conference on power electronics, machines and drives (PEMD 2014). IET; 2014. p. 1-6.

[215] Xie K, Jiang Z, Li W. Effect of wind speed on wind turbine power converter reliability. IEEE Trans Energy Convers 2012;27(1):96-104. http://dx.doi.org/ 10.1109/TEC.2011.2179656.

[216] Musallam M, Johnson C. Impact of different control schemes on the life consumption of power electronic modules for variable speed wind turbines. In: Proceedings of the 2011-14th European conference on power electronics and applications (EPE 2011); 2011. p. 1-9.

[217] Fischer K, Stalin T, Ramberg H, Wenske J, Wetter G, Karlsson R, et al. Fieldexperience based root-cause analysis of power-converter failure in wind turbines. IEEE Trans Power Electron 2015;30(5):2481-92. http://dx.doi.org/ 10.1109/TPEL.2014.2361733.

[218] Feltes C, van de Sandt R, Koch F, Shewarega F, Erlich I. Neutral grounding in wind farm medium voltage collector grids. In: Proceedings of power systems conference and exposition (PSCE). IEEE/PES, IEEE; 2011. p. 1-7.

[219] Ayers DE, Dickinson M. Wind farm transformer design considerations; 2011. URL 〈http://www.power-eng.com/articles/print/volume-115/issue-11/fea tures/wind-farm-transformer-design-considerations.html $\rangle$.

[220] Smugala D, Piasecki W, Ostrogorska M, Florkowski M, Fulczyk M, Granhaug $\mathrm{O}$. Wind turbine transformers protection method against high-frequency transients. IEEE Trans Power Deliv 2015;30(2):853-60. http://dx.doi.org 10.1109/TPWRD.2014.2343261.

[221] Singh J, Sood Y, Jarial R. Condition monitoring of power transformers-bibliography survey. IEEE Electr Insul Mag 2008;3(24):11-25.

[222] Djebarri S, Charpentier J, Scuiller F, Benbouzid M. A systemic design methodology of pm generators for fixed-pitch marine current turbines. In: Proceedings of the 2014 international conference on green energy; 2014. p. 3237. 〈http://dx.doi.org/10.1109/ICGE.2014.6835393〉.

[223] Galloway PW, Myers LE, Bahaj AS. Quantifying wave and yaw effects on a scale tidal stream turbine. Renew Energy 2014;63:297-307. http://dx.doi. org/10.1016/j.renene.2013.09.030.

[224] Pao LY, Johnson K. Control of wind turbines. IEEE Control Syst 2011;31(2):4462. http://dx.doi.org/10.1109/MCS.2010.939962.

[225] Entezami M. Novel operational condition monitoring techniques for wind turbine brake systems [Ph.D. thesis]; 2013.

[226] Entezami M, Hillmansen S, Weston P, Papaelias M. Fault detection and diagnosis within a wind turbine mechanical braking system using condition monitoring. Renew Energy 2012;47:175-82. http://dx.doi.org/10.1016/j. renene.2012.04.031.

[227] Godwin JL, Matthews P. Classification and detection of wind turbine pitch faults through scada data analysis. IJPHM Spec Issue Wind Turbine PHM 2013:90.

[228] Odgaard P, Johnson K. Wind turbine fault detection and fault tolerant contro - an enhanced benchmark challenge. In: Proceedings of American control conference (ACC); 2013. p. 4447-52. 〈http://dx.doi.org/10.1109/ACC.2013. $6580525\rangle$

[229] Shi F, Patton R. A robust adaptive approach to wind turbine pitch actuator component fault estimation. In: Proceddings of the 2014 UKACC international conference on control; 2014. p. 468-73.

[230] Laouti N, Othman S, Alamir M, Sheibat-Othman N. Combination of modelbased observer and support vector machines for fault detection of wind turbines. Int J Autom Comput 2014;11(3):274-87. http://dx.doi.org/10.1007/ s11633-014-0790-9.

[231] Wu X, Li Y, Li F, Yang Z, Teng W. Adaptive estimation-based leakage detection for a wind turbine hydraulic pitching system. IEEE/ASME Trans Mechatron 2012;17(5):907-14. http://dx.doi.org/10.1109/TMECH.2011.2142400.

[232] Kim M, Dalhoff P. Yaw systems for wind turbines? Overview of concepts, current challenges and design methods J Phys: Conf Ser 2014;524.

[233] Kragh KA, Hansen MH, Mikkelsen T. Improving yaw alignment usingspinnerbased lidar; 2011.

[234] Galvez-Carrillo M, Rakoto L, Kinnaert M. Switzerland. In: Luo N, Vidal Y, Acho 
L, editors. Wind turbine control and monitoring, advances in industrial control. Switzerland: Springer International Publishing; 2014.

p. 267-99. http://dx.doi.org/10.1007/978-3-319-08413-8 10.

[235] Wei X, Verhaegen M, Van den Engelen T. Sensor fault diagnosis of wind turbines for fault tolerant. In: Proceedings of the 17 th world congress the international federation of automatic control. Vol. 17; 2008. p. 3222-27.

[236] Odgaard PF, Stoustrup J, Nielsen R, Damgaard C. Observer based detection of sensor faults in wind turbines. In: Proceedings of European wind energy conference; 2009. p. 4421-30.

[237] Saberi A, Salmasi F, Najafabadi T. Sensor fault-tolerant control of wind turbine systems. In: Proceedings of the 5th Conference on thermal power plants (CTPP); 2014. p. 40-45. 〈http://dx.doi.org/10.1109/CTPP.2014.7040693〉.

[238] Galloway G, Catterson V, Love C, Robb A. Anomaly detection techniques for the condition monitoring of tidal turbines. In: Proceddings of Annual Conference of the Prognostics and Health Management Society (PHM); 2014.

[239] Duhaney J, Khoshgoftaar T, Napolitano A. Studying the effect of class imbalance in ocean turbine fault data on reliable state detection. In: Proceedings of the 2012 11th international conference on machine learning and applications (ICMLA). Vol. 1; 2012, p. 268-75. 〈http://dx.doi.org/10.1109/ ICMLA.2012.53>. 